\title{
Ageing across the UK
}

By James Bayliss and Frances Sly, Office for National Statistics

\begin{abstract}
The wellbeing of the older population in the UK is a priority to local and national government and health authorities, as well as to people themselves. The population aged over 65 is progressively becoming a larger percentage of the nation's population. The effects of falling mortality rates are especially visible among the 'oldest old'. At the same time, however, the older population is supported by a shrinking labour force.

This article explores regional and sub-regional variations in the concentration of older people. The populations of London and Northern Ireland have smaller proportions of older people than other regions. The South West and Wales have higher proportions and local authority level data suggest a pattern of settlement in coastal and rural areas. Population projections indicate, on the basis of past trends, the expected future growth in the population at older ages.

The article also investigates measures of wellbeing of the ageing population including benefits and income deprivation, life expectancy, aspects of health and social care, older workers, and qualifications and learning. At local authority and small area level, variations in the older population often appear to correspond to the rural or urban nature of the areas concerned. The article includes case studies of income deprivation of older people at Lower Layer Super Output Area (LSOA) level in the North West and the South East regions.
\end{abstract}

\section{Notes}

Unless otherwise stated the data used in this article were those available at the time of writing. In particular, mid-year population estimates were those released in August 2009.

The authors would like to thank colleagues in contributing departments and organisations for their generous support and helpful comments without which this article would not have been possible.

\section{Introduction}

The population of the UK is becoming increasingly older. This is a cause for celebration but population ageing also presents a new set of challenges, for example: access to local services, housing, health and welfare services. Over the last 25 years, the number of people aged 65 and over in the UK has increased by 18 per cent, from 8.4 million to 9.9 million in 2008. In the same period, the population aged 16-64 increased by 11 per cent while the under 16 population decreased by 5 per cent.

Decreases in infant and childhood mortality and, from the middle of the 20th century, mortality at older ages contributed to larger numbers of people surviving to old age. Most striking is the growth in the number of very old people. Since 1983 the numbers of people aged 85 and over (sometimes described as the 'oldest old') have more than doubled, to reach 1.3 million in 2008. As a proportion of the total population, they have increased from 1.1 per cent to 2.2 per cent over the past 25 years. There were 410,000 people aged 90 and over in 2008, of whom over 10,000 were centenarians.

The post-World War II 'baby boom' generation has started to reach retirement age and the 1960s baby boom generation will be another boost to the older population in future decades. Fertility levels declined after the mid-1960s, reaching their lowest levels in the mid-1970s; they have been increasing since 2001 but are still below replacement level (the level at which a couple has only enough children to replace themselves). Thus the younger cohorts contain fewer people than those aged around 40, and hence there are likely to be fewer people working to help support the retired population in future, unless steps are taken such as raising the retirement age.

Population ageing is an important issue facing planners and service providers at national, regional and local levels across the UK. The older population is becoming an ever-larger focus of UK government policy. Provision of health and social care, the raising of retirement ages, and incentives for more people aged over 50 (termed 'older workers') to remain in employment are among the many issues facing the government. The demographic changes will be different and will have a range of effects on services in the various countries and regions, as well as in different types of local area.

This article examines the differences between the UK countries and English regions in the current age structure of the population and the projected ageing of the population up 
to 2031. The article goes on to describe a number of key statistics relevant to the older working-age and retired populations in the early 21st century. The devolution of most areas of policy-making and service provision mean that comparable statistics are not available for all topics across the whole of the UK and in some cases data are considered for England or England and Wales only.

Broadly speaking, the article considers the population aged 50 and over. Those currently aged 50 and over in the regions are a very good guide to what their populations aged 65 and over will be in 15 years time, subject only to relatively low rates of death and (mainly inter-regional) migration.

The most commonly used definition of old age is the age at which a person becomes entitled to receive state pension benefits - state pension age (SPA), currently 65 for men and, until 2009, 60 for women. From 2010 the pension age for women is being gradually increased until it reaches 65 in 2020 (Box 1). The majority of population statistics in this article are divided into two groups therefore, above and below the age of 65. The group aged under SPA or under 65 can be described as 'young older people'. Those aged 65 and over (or sometimes 60 and over) may be referred to in this article simply as 'old', although it is recognised that subjectively many people in their sixties do not feel 'old'.

Labour market data are shown for young older people, aged 50 to SPA (known also as 'older workers'); the numbers of people above SPA in employment is too small to be identified accurately at regional level. The majority of policy issues relate to provision for the increasing numbers of people aged 65 and above, so projections of population growth are also considered for this age group. Some datasets are available only for those aged 65 and over, for example hip and knee replacements, social care and influenza vaccination take-up.

\section{Box 1: State pension age}

By the time this article is published in June 2010, the definition of state pension age for women will have started to change from that previously adopted. As this article uses population and pension data for 2008, statistics have been presented with reference to the definition of State Pension Age that was in use in 2008; 60 for women and 65 for men.

The change in female state pension age starts from 6 April 2010. From that point, the state pension age for females will increase by 1 month every 2 months for the next 10 years; this will result in a total 5-year increase from 60 to 65 by April 2020. So, in April 2010, it will become 60 years 1 month, in June 2010 it becomes 60 years 2 months and so on.

Phased increases in the state pension age for men and women are due to be introduced by the UK government between 2024 and 2046.
Many of the key 'life events' (for example, loss of a spouse or partner or retirement) are now occurring at older ages than in the past. It is therefore useful to divide the population aged 65 and over into smaller age bands, for example, 65-74, 75-84 and 85 and over. The latter are known as the 'oldest old'. However, at a regional level many data are difficult to obtain for these smaller age groups and issues of disclosure control and statistical uncertainties become more prominent.

Information on levels of poverty and income deprivation is presented for the population aged 60 and over using data on receipt of key government benefits, fuel poverty and households below 60 per cent of median income. The Income Deprivation Affecting Older People Index (IDAOPI) provides insight into smaller geographic areas which have the largest numbers of the most deprived people aged 60 and over. IDAOPI also allows the incidence of income deprivation among the over 60 s to be examined by the Rural/Urban Definition of the area.

\section{Population}

All countries of the UK and English regions show evidence of population ageing, but the change has not occurred evenly across the country and the concentration of older people varies. Regional differences may be smaller than differences between urban and rural areas as a result of geographic, economic and social factors that have shaped communities over time.

\section{Geographic distribution of the older population}

People aged 50 and over made up at least one-quarter of the population in each region and country of the UK in 2008. Most regions had proportions close to the UK average of 34 per cent. The lowest percentages were found in London at 26 per cent and Northern Ireland at 31 per cent. The highest percentages were found in the South West (39 per cent) and Wales (37 per cent).

The region with the largest population aged 50 and over was the South East (2.9 million), also the region with the largest total population. But while London had the next largest total population, it ranked fifth on population aged 50 and over, at 2.0 million.

The UK population aged 50 and over increased by 5.1 per cent in the five years between 2003 and 2008, from 20 million to just over 21 million. In comparison the population of all ages increased by 3.1 per cent over the same five-year period. All UK countries and English regions saw increases in the population aged 50 and over; in most, the increases were close to the average. The largest percentage increase was in Northern Ireland (8.7 per cent). In England, the largest regional increases were in the East (6.6 per cent) and the East Midlands (6.4 per cent). The smallest percentage increases occurred in London and the North West, at 2.5 and 3.3 per cent respectively. 
Map 1.1 Percentage of the population aged 50 and over: by local authority, UK, 2008

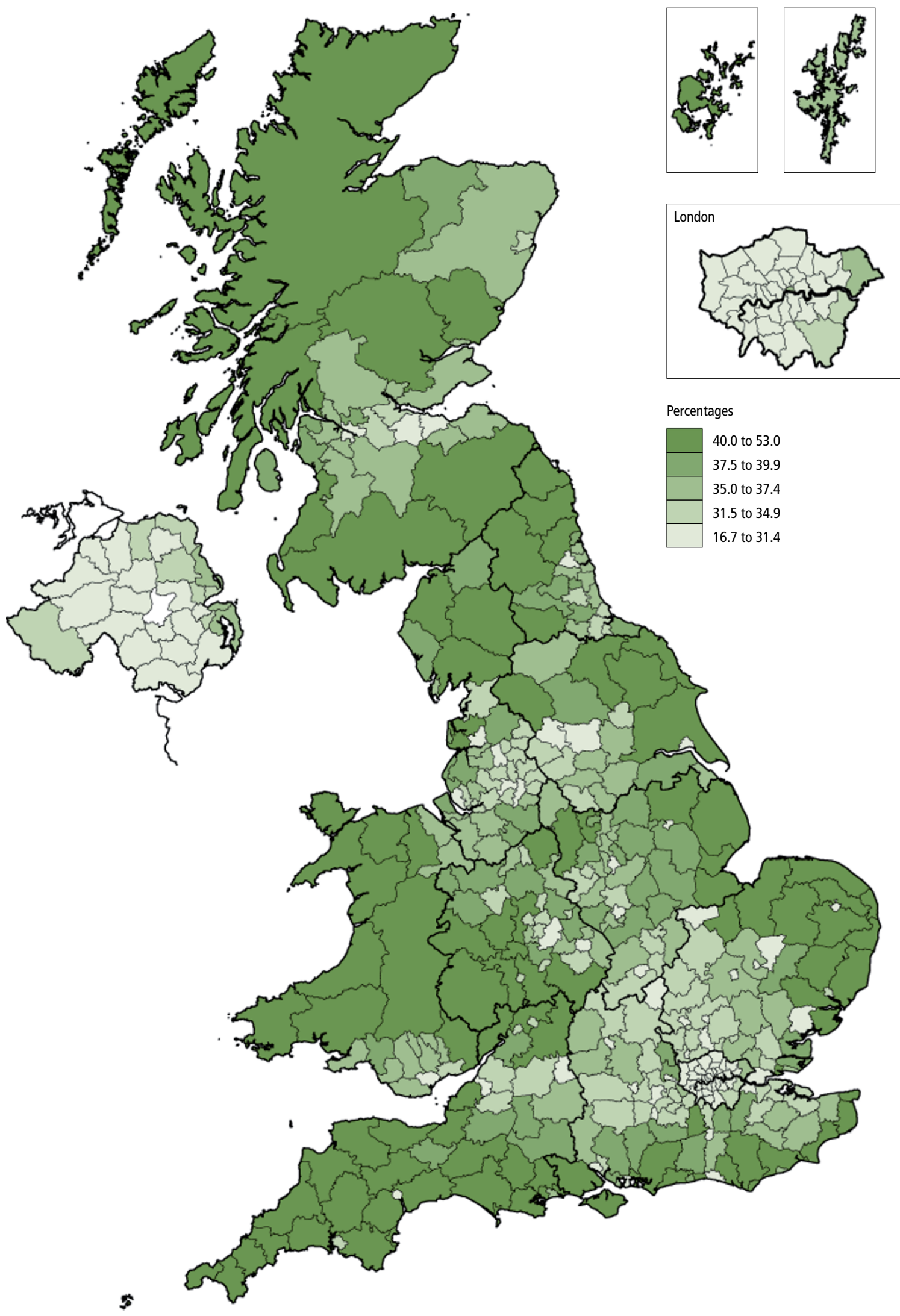


Map 1.1 shows the percentage of the population aged 50 and over at local authority and district level. Coastal and rural areas had the highest percentages of population aged 50 and over, except such areas in Northern Ireland. The highest percentages were seen in West Somerset (53 per cent), North Norfolk (51 per cent), Rother (East Sussex; 50 per cent) and Christchurch (50 per cent). These are the only local authorities with more than 50 per cent of their population aged 50 and over. These higher percentages were partly because of internal migration of people of retirement age within the UK over a period of many years.

The higher percentage of older people in the coastal and rural areas of Great Britain contrasts with lower levels found in London (for example, Tower Hamlets, 17 per cent; Lambeth, 20 per cent; Newham, 20 per cent), and around urbanised areas of central England, most notably Nottingham, 25 per cent; Manchester and Oxford both 23 per cent. The lowest levels in Wales, Scotland and Northern Ireland were equivalent to some others in the midlands and north of England. Cardiff (29 per cent); City of Edinburgh (31 per cent); and Glasgow (30 per cent) compare to Leeds, Bradford, Coventry (all 30 per cent); Blackburn and Darwen, Milton Keynes (both 29 per cent); and Birmingham (28 per cent). The majority of Northern Ireland districts had similar levels and the lowest value was 27 per cent in Dungannon, Newry and Mourne, Derry and Magherafelt.

\section{Population by age}

One of the features of population ageing is the increasing numbers in the oldest age groups. Although much smaller in number, they are important because this is where most growth is projected to take place in the future. These age groups also tend to be those that are heavily reliant on health and care services. The age distribution varies between regions for a variety of reasons including historical differences in fertility, mortality and migration (Online tables 10.9. $10.10,10.6$ respectively). Figure 1.2 shows the proportions of the total population represented by the age groups 50-64, 65-74, 75-84 and 85 and over.

The South West consistently had the largest percentages in each age group considered. For the two oldest age groups (75-84 and 85 and over), the South West stands out as having markedly higher percentages than all other regions (6.7 per cent compared with 5.6 per cent for the UK and 2.8 compared with 2.2 per cent respectively). Wales had the second largest percentages except among the oldest old (85 and over), where the South East (2.5 per cent) ranked second, with Wales close behind (2.4 per cent).

London and Northern Ireland consistently had the lowest percentages in each group, with each having only 1.6 per cent of their population aged 85 and over. For the three younger age groups considered, London's percentages were lower than any other region or country: 14.2 per cent for age 50-64 (compared with 18.0 per cent for the UK); 5.9 per cent (UK 8.4 per cent) for 65-74; and 4.1 per cent (UK 5.6 per cent) for 75 to 84 .

In Scotland, the percentages of the population in the three age groups covering ages 50 to 74 were at, or above, the UK averages but for the oldest old the percentage was lower in Scotland (1.9 per cent) than in the UK (2.2 per cent).

\section{Figure 1.2}

\section{Percentage of total population in key age groups, 2008}

Percentages

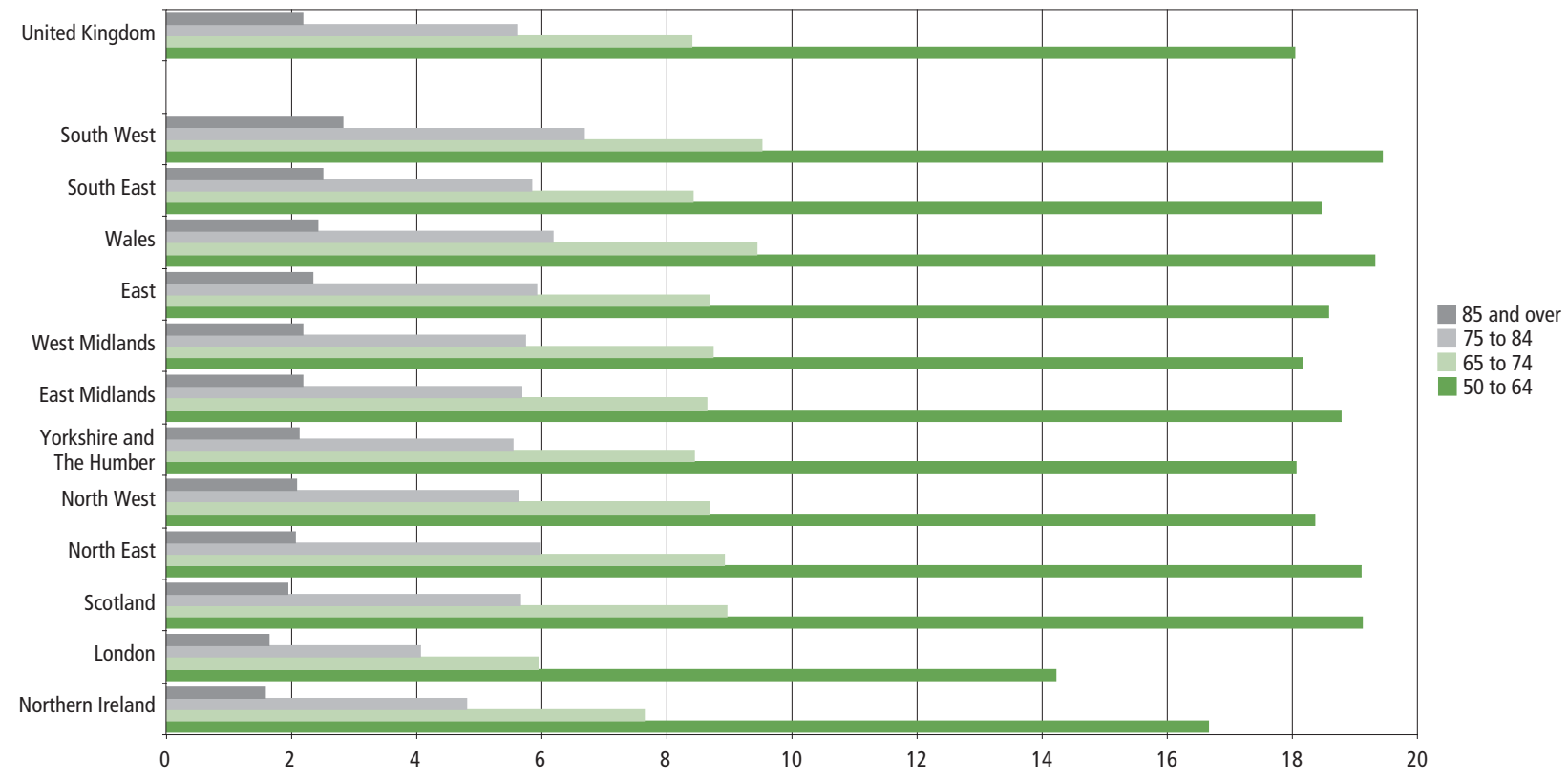

Source: Office for National Statistics 


\section{Box 2: Defining areas by rurality}

The constituent countries of the UK define their geographic small areas in terms of rurality in different ways. Each country does, however, use definitions based upon a small area's proximity to major urban areas and/or its population size as a means to defining it as rural or urban. However, different thresholds to the physical distance to settlements, and/or population size may be adopted.

\section{England and Wales - Rural/Urban Definition} (www.statistics.gov.uk/geography/nrudp.asp; www.defra.gov.uk/evidence/statistics/rural/ruraldefinition.htm\#defn)

The full definition uses settlements with a population of 10,000 persons, and population density in 1 hectare squares across both countries to define land areas into six different levels of rurality.

MSOA-level population estimates used to create Figure 1.3 and Figure 1.4 are experimental statistics. These do not yet meet the quality standards for designation as National Statistics.

\section{Scotland - Urban Rural Classification} (www.scotland.gov.uk/Publications/2004/06/19498/ 38784)

The full definition uses population thresholds at 3,000, 10,000 and 125,000 people and a drive-time threshold of 30 minutes to a settlement for classifying their Data Zones into six categories of rurality.

Scottish small area population estimates used to create Figure 1.5 are not National Statistics.

\section{Northern Ireland - Urban-Rural Classification} (www.nisra.gov.uk/geography/default.asp10.htm)

Rurality is based upon proximity to areas defined as settlements, and a general consensus that divide between urban and rural lines among settlements whose populations are between 3,000 and 5,000 persons.

Northern Ireland small area population estimates defined at a Settlement level and used to create Figure 1.6 are not National Statistics.

\section{Population by Rural/Urban Definition}

Figure 1.3 shows the estimated percentages of people aged under 50, 50-64 and 65 and over by Rural/Urban Definition at Middle Layer Super Output Area (MSOA) level in England in 2008 (Box 2). About 76 per cent of the population in the 50-64 and 65 and over age groups lived in areas defined as 'Urban over 10,000 [population]'. The remaining population in these age groups was divided approximately equally between 'Town and Fringe' areas (10 per cent) and 'Village,
Figure 1.3

Population: by Rural/Urban Definition at MSOA level, England, 2008

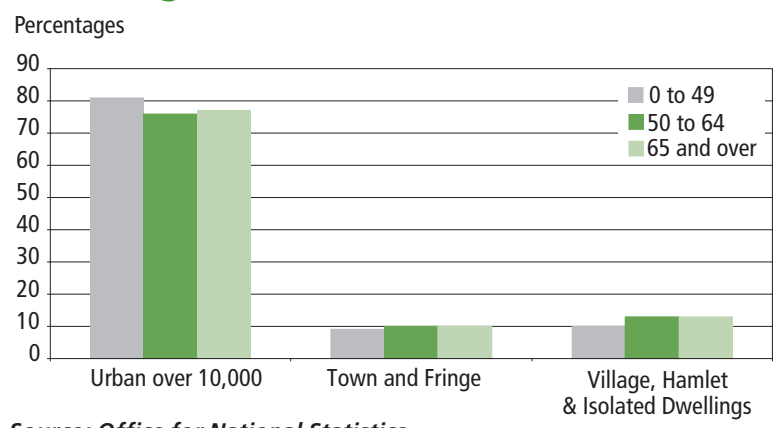

Source: Office for National Statistics

\section{Figure 1.4}

Population: by Rural/Urban Definition at MSOA level, Wales, 2008

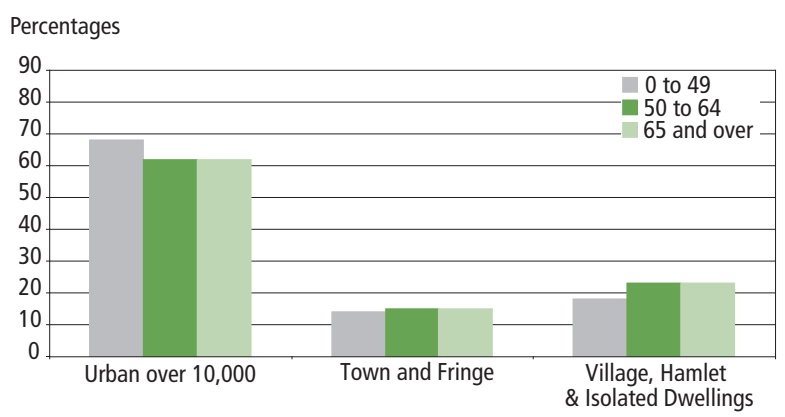

Source: Office for National Statistics

\section{Figure 1.5}

Population: by Urban Rural Classification ${ }^{1}$ at Data Zone level, Scotland, 2008

Percentages

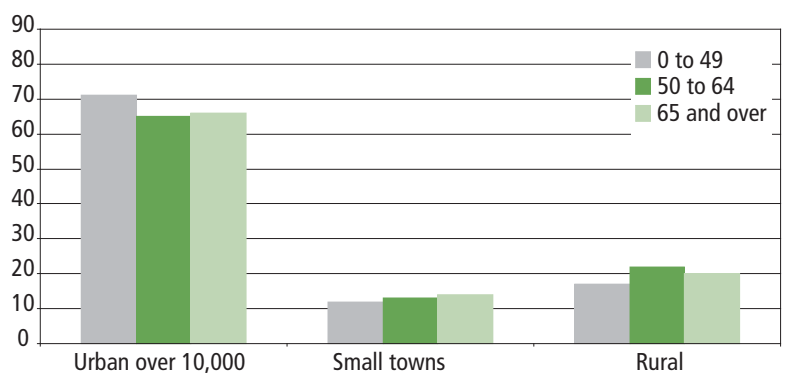

1 Using 2007/08 classification.

Source: Scottish Government

Figure 1.6

Population: by Urban-Rural Classification by settlements, Northern Ireland, 2001'

Percentages

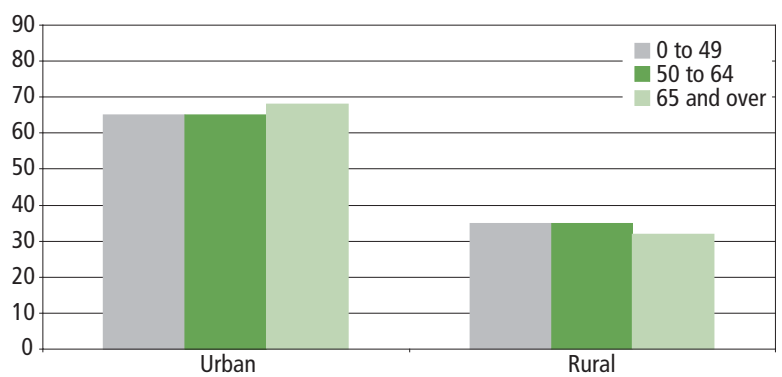

12001 Northern Ireland Census estimates.

Source: Northern Ireland Statistics and Research Agency 
Hamlets and Isolated Dwellings' (13 per cent). This compares with 81 per cent, 9 per cent and 10 per cent respectively for the population of England aged under 50.

Using the same Rural/Urban Definition as England, the age 50 and over population of Wales (Figure 1.4) is divided into 62 per cent in 'Urban over 10,000 [population]', 15 per cent in 'Town and Fringe' and 23 per cent in 'Village, Hamlets and Isolated Dwellings' compared with 68 per cent, 14 and 18 per cent respectively of Wales' population aged under 50 .
Figure 1.5 illustrates Scotland's 2008 population divided into the same age groups, and classified using its own 2007/08 Urban Rural Classification by its Data Zone small area geography (Box 2). Again, the majority of the 50 and over population lived in urban areas (66 per cent, compared with 71 per cent for the under 50 population).

Northern Ireland uses a different method again for small area Urban-Rural Classification (Box 2). However, population estimates for Northern Ireland classified in this way have not been made since the 2001 Census, and so are seven years out

\section{Figure 1.7}

\section{Projected ${ }^{1}$ population change for men and women aged 50 and over, 2006 to 2031} Percentages
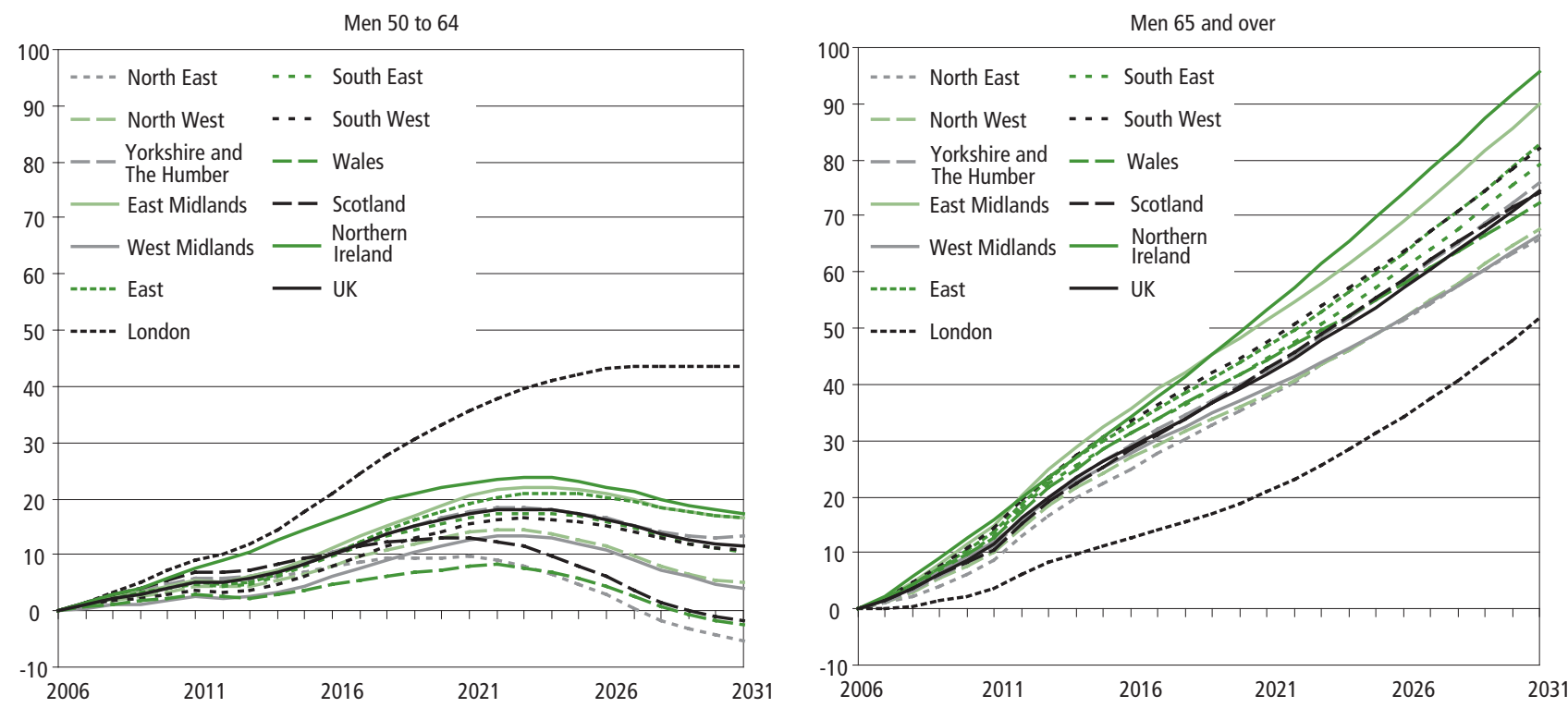

Women 50 to 64

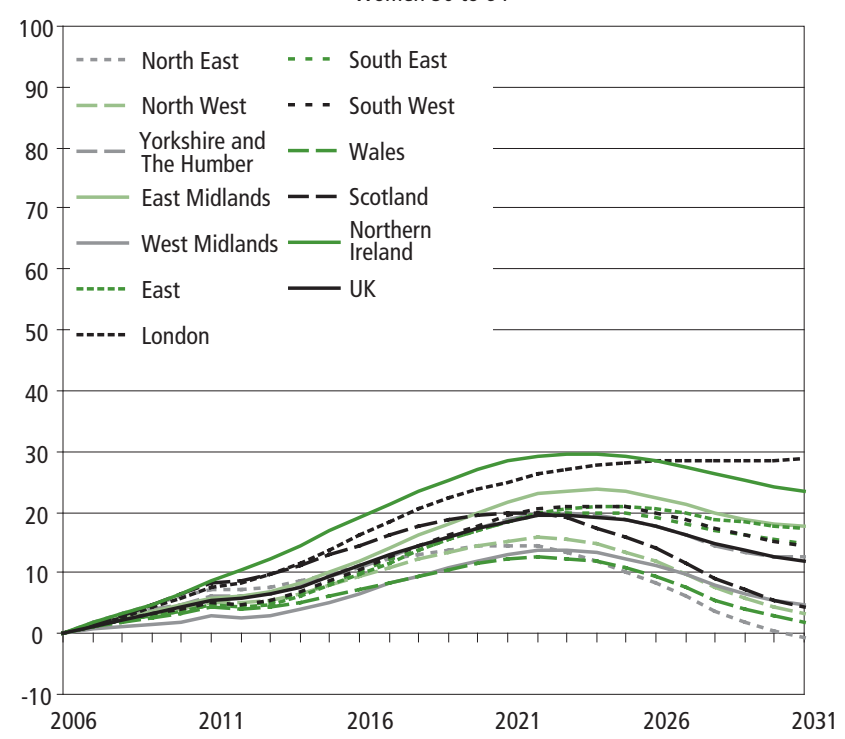

1 Based on 2006 population estimates.

Source: Office for National Statistics

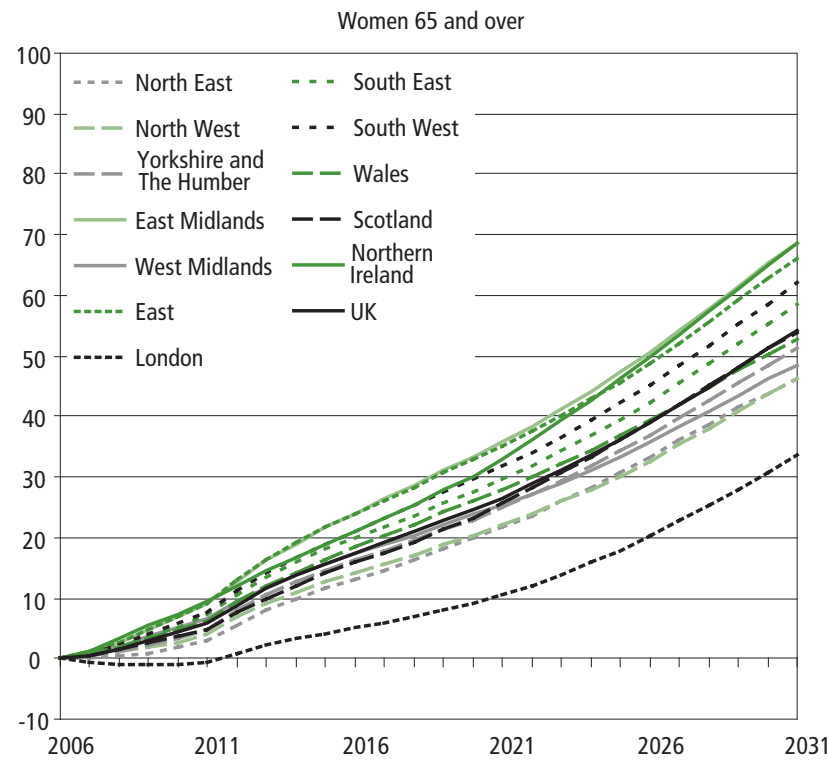

3 Although 2008-based National Population Projections (NPP) have been published, 2008-based Subnational Population Projections (SNPP) were not available at the time of writing. The projections for UK countries shown here are 2006-based NPP to be consistent with the regional projections. 


\section{Figure 1.8}

\section{Projected ${ }^{1}$ population change for men and women aged 75 and over, 2006 to 2031} Percentages
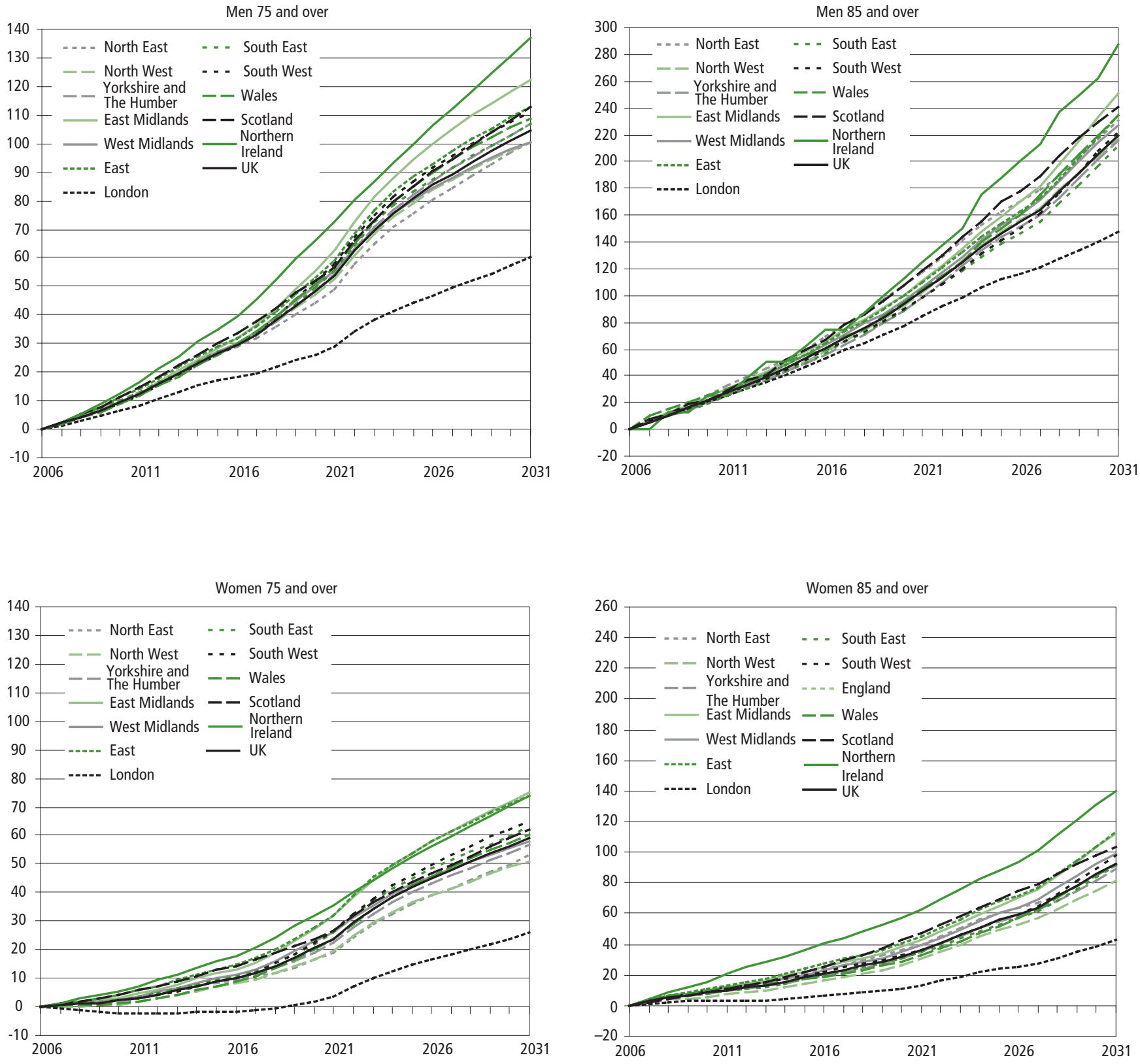

1 Based on 2006 population estimates.

Source: Office for National Statistics

of date relative to the three other countries of the UK. These are given in terms of level of rurality at output area level in Figure 1.6. Two-thirds of Northern Ireland's population lived in these urban areas in 2001 and this did not vary between the age groups shown.

\section{Population projections}

Population ageing is projected to continue, with the number of people in the UK aged 65 and over increasing by nearly two-thirds to reach 15.8 million by 2031 . By this time, those aged 65 and over will account for 22 per cent of the UK population.
The greatest population increases are projected for the oldest of the older age groups. By 2031 a 77 per cent increase is expected in the number of those aged 75 and over and a 131 per cent increase in those aged 85 and over.

Projected increases in the number of old people, together with past falls in fertility rates, mean the average age of the UK population is also expected to continue to rise (www.statistics.gov.uk/ageingintheuk/default.htm).

Women in older age groups outnumber men because, on average, women have a greater life expectancy. However, with improvements in male life expectancy this differential is projected to decrease. By 2031 the number of women aged 


\section{Figure 1.9}

Age-specific death rates: by age group, 2008

Deaths per 1,000 population

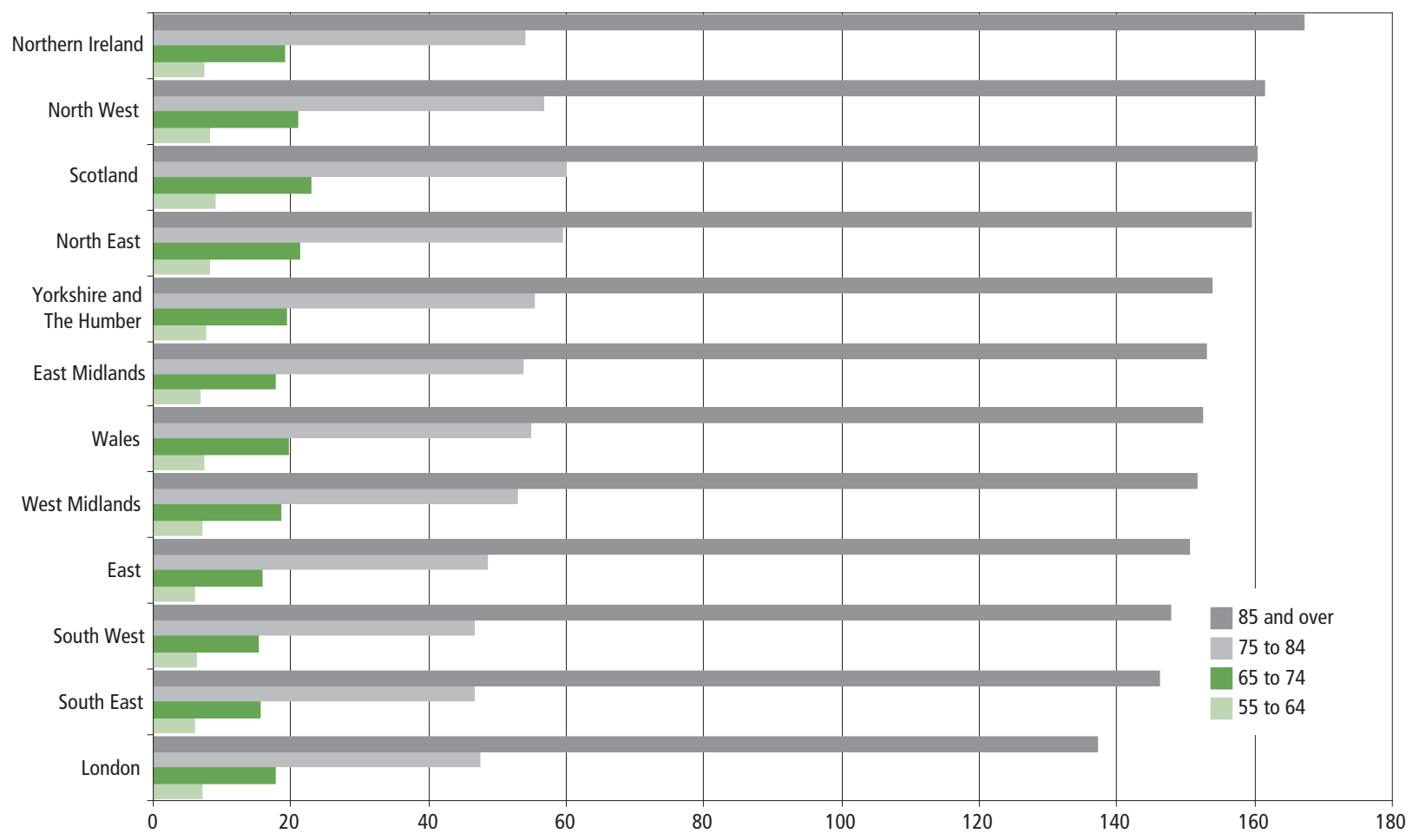

Source: Office for National Statistics; General Register Office for Scotland; Northern Ireland Statistics and Research Agency

65 and over is projected to increase by 54 per cent compared with a 74 per cent increase in men of this age. This effect is even more pronounced for the oldest old with projected increases of 93 per cent in women aged 85 and over, compared with a 220 per cent increase in men aged 85 and over by $2031 .{ }^{3}$

Figures 1.7 and 1.8 illustrate regional population projections for men and women aged 50-64, 65 and over, 75 and over and 85 and over in terms of percentage increase in the population from 2006. The data for each region are available as a supplementary table on the ONS website.

London is projected to experience markedly different patterns of population growth from the other regions and countries. For the 50-64 age band, this region is projected a greater population increase than other regions; growth of its more elderly age groups is projected to be slower than other regions.

Between 2006 and 2031 the projected increase in the London population aged 50-64 is 44 per cent for men and 29 per cent for women (compared with the UK average of a 12 per cent for both sexes in this age band). Outside London, Northern Ireland, the East and the East Midlands show the largest projected increases in this age group between 2006 and 2031. For men, the projected increase is 17 per cent in all three areas and for women 24 per cent in Northern Ireland and 18 per cent in the East and the East Midlands.
Wales, Scotland, and the North East show little change in the population aged 50-64 between 2006 and 2031. The 50-64 male populations of Wales and Scotland are projected to reduce in size by about 2 per cent on 2006 population sizes, the North East by about 5 per cent. The female populations in this age group are expected to increase by 2 to 4 per cent on 2006 estimates in the two countries and to reduce by 1 per cent in the North East.

For those aged 65 and over, London has the lowest projected increases between 2006 and 2031; a 52 per cent increase in men and 34 per cent increase in women. These projected increases are notably below the UK average of 74 per cent and 54 per cent respectively. Northern Ireland, the East Midlands and the East are projected to have the highest increases in this age group, 96 per cent for men and 69 per cent for women in Northern Ireland and for the East Midlands and the East 90 per cent and 83 per cent respectively for men, and 69 per cent and 66 per cent respectively for women.

The 65 and over age group is narrowed down into older sub-groups - 75 and over, and 85 and over - in Figure 1.8. Projected growth in each of these age groups is close to the UK average in most regions. In London, the number of men aged 75 and over is projected to increase by 60 per cent in this 25-year period and the number of women aged 75 and over by 26 per cent. Northern Ireland is projected markedly 
Figure 1.10

\section{Net internal migration of people aged 50 and over, mid-2007 to mid-2008}

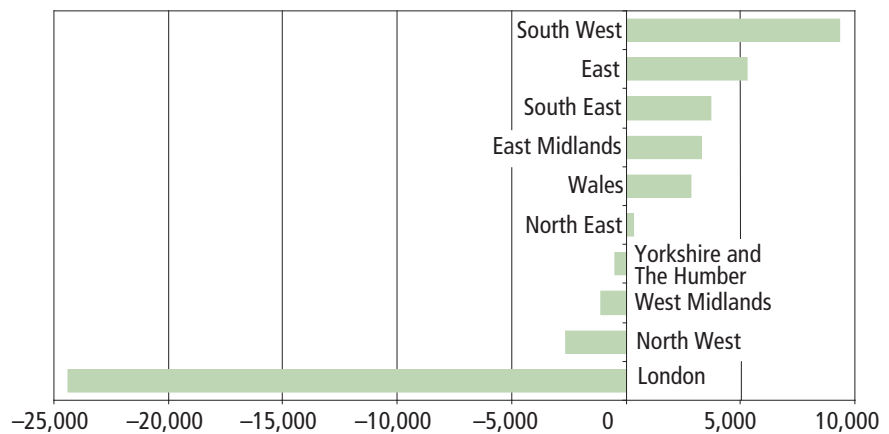

Source: Office for National Statistics

greater than average population increases of 137 per cent and 74 per cent for men and women respectively.

In the 85 and over age group, Northern Ireland continues the trend shown for the other age groups considered, exhibiting a noticeably greater projected increase than all other UK regions and countries (291 per cent for men and 139 per cent for women). At the other extreme, in London the projected increases are 147 per cent and 42 per cent respectively.

\section{Factors affecting population change}

Age-specific death rates are available for 10-year age bands by English region and UK country. Figure 1.9 presents age-specific death rates per 1,000 people aged 55-64, 65-74, 75-84 and 85 and over in 2008. Generally, excluding London from consideration, age-specific death rates increased in the regions of England from south to north, regardless of the age group considered. London had the lowest rate for those aged 85 and over (137 per 1,000 compared with the UK average of 152 deaths per 1,000), below other southern regions (146 in the South East, 148 in the South West and 151 in the East). For the two lowest age groups considered, the death rates in London equalled the UK and England averages and were above those of the other southern regions. Death rates in Scotland were the highest in all age groups, closely followed by the North West and the North East, except for those aged 85 and over, where Northern Ireland had the highest rate (Online table 10.10).

Figure 1.10 presents net internal migration for those aged 50 and over between mid-2007 and mid-2008 between the English regions and Wales. These data are not National Statistics, but are presented as an example of annual movements between regions to aid understanding of the different regional patterns of population growth for older people. In net terms (after subtracting those entering from those leaving), almost 25,000 people aged 50 and over left London in this annual period. This was by far the highest net internal migration, 10 times the net outmigration for the next highest region (the North West, 3,000 people).
The regions with the greatest increase from internal migration of those aged 50 and over were the South West (net internal in-migration of 9,000) and the East, the South East, the East Midlands and Wales (net in-migration ranging from 5,000 down to 2,000 people respectively).

\section{Demographic characteristics}

In 2008, 71 per cent of men in the UK aged 65 and over were married and living with their spouse. The equivalent proportion for women aged 65 and over was much lower at 46 per cent. Conversely, the proportion of women aged 65 and over who were widowed was much higher than the equivalent proportion of widowed men, (40 per cent and 16 per cent respectively) (Figure 1.11). These differing patterns for older men and women are a result of the tendency for women to live longer than men and also to marry men older than themselves.

The proportions of single, never-married men and of single never-married women aged 65 and over were very similar ( 6 per cent and 5 per cent respectively) as were the proportions of men and women of this age group who were divorced or separated (8 per cent and 9 per cent respectively).

The pattern of marital status described for men and women aged 65 and over in the UK was broadly mirrored across the UK countries and English regions; there were a few regional variations, however. These may well be due to slightly differing age profiles within the population aged 65 and over across the regions and countries. The biggest marital status variations from the average were for London and Northern Ireland.

London had higher proportions of men and women aged 65 and over who were single and never married than other regions, at 11 per cent for men (compared with the UK average of 6 per cent) and 9 per cent for women (compared with 5 per cent). In this age group, London also had the highest proportions of divorced and separated people 10 per cent of men and 12 per cent of women; these proportions were slightly above the respective UK averages of 8 per cent and 9 per cent. London had the lowest proportions of men and women aged 65 and over who were married and living with their partner, 63 per cent of men (compared with the UK average of 71 per cent) and 37 per cent of women (compared with 46 per cent).

Northern Ireland also had relatively high proportions of men and women aged 65 and over who were single and never married, at 9 per cent for both sexes. However, Northern Ireland had the lowest proportions of men and women aged 65 and over who were divorced and separated, 4 per cent of men (compared with the UK average of 8 per cent) and 5 per cent of women (compared with 9 per cent). It also had relatively low proportions of men and women who were married and living with their spouse. 


\section{Figure 1.11}

\section{Legal marital status for men and women ${ }^{1}$ aged 65 and over, 2008}

Percentages
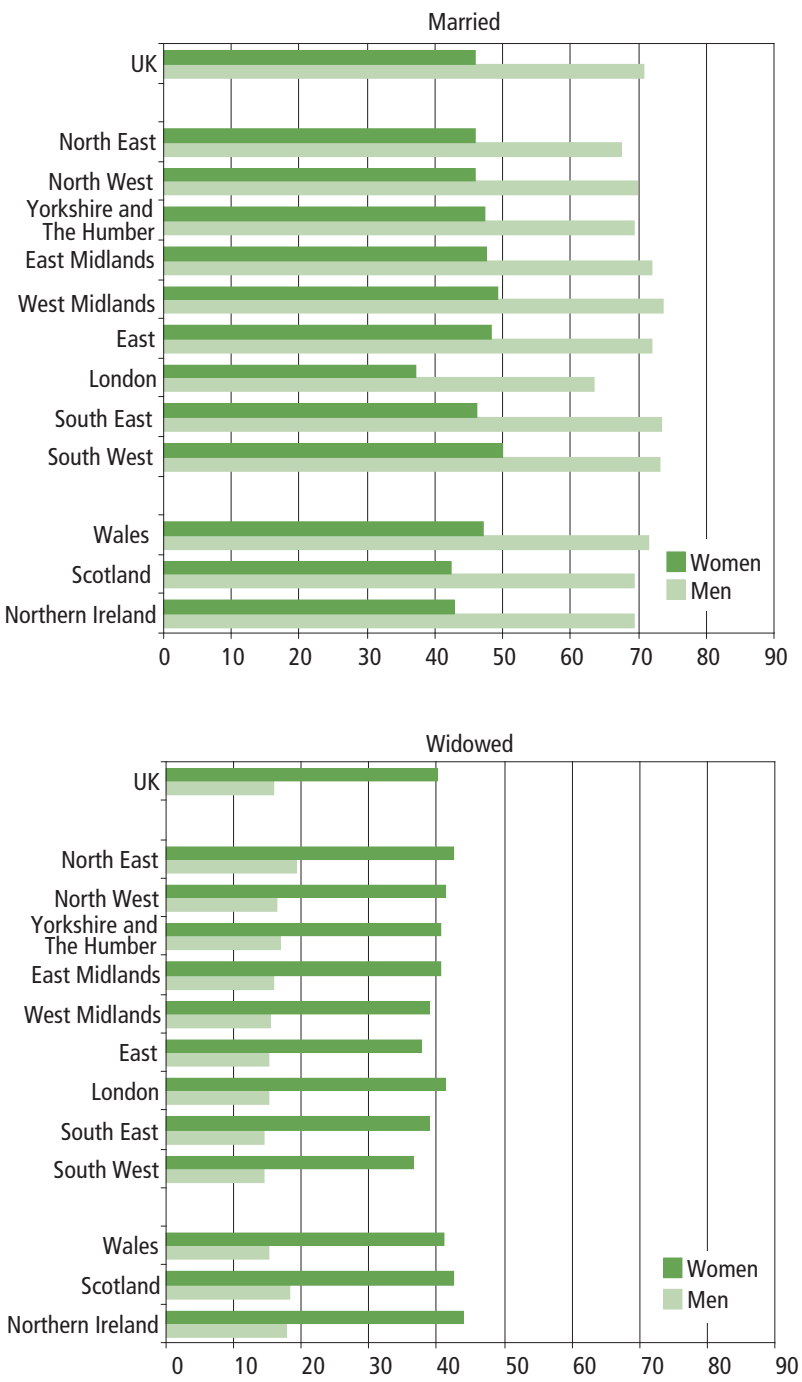
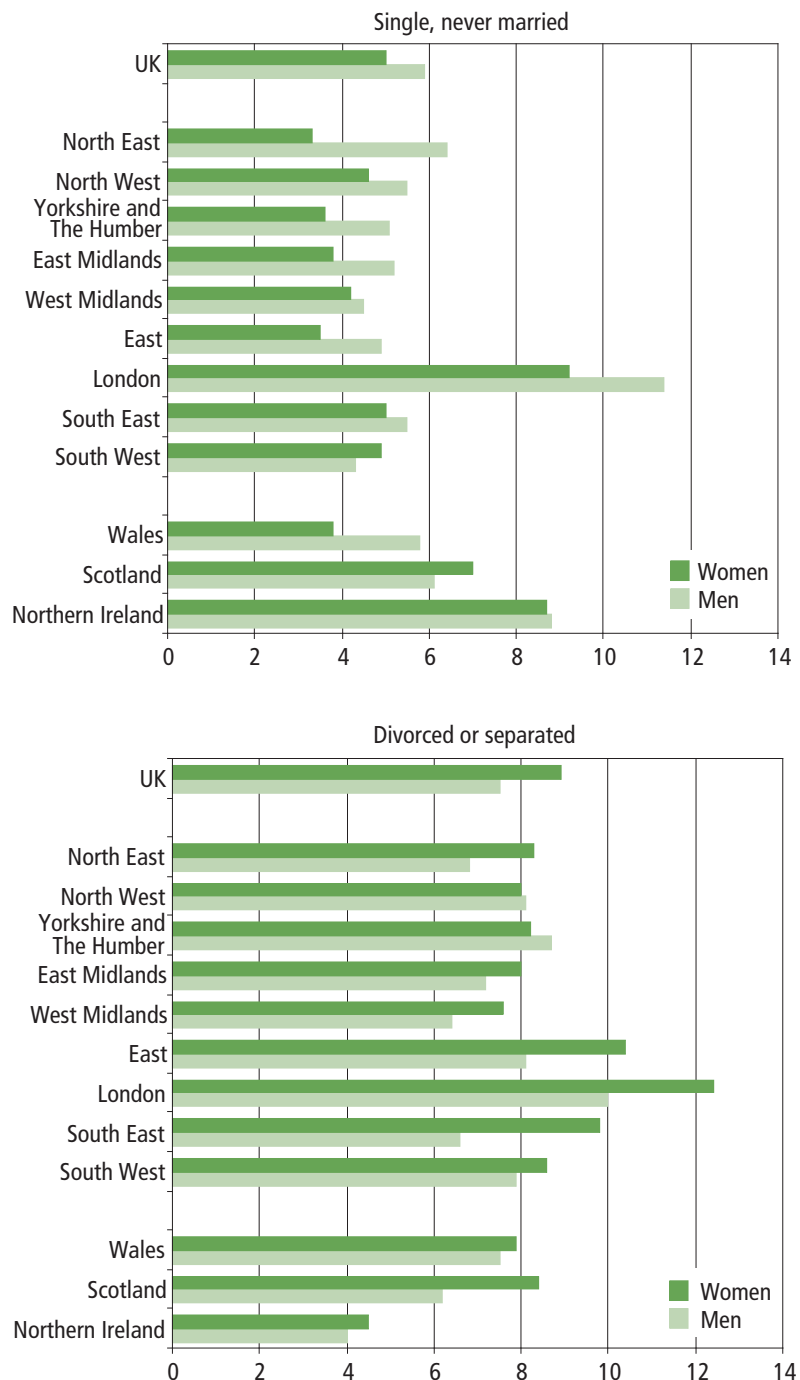

1 Married, living with husband/wife includes civil partnerships; Divorced or separated includes separated civil partnerships and legally dissoved civil partnerships; Widowed includes surviving civil partners.

Source: Annual Population Survey, Office for National Statistics

The distribution of the population aged 50 and over by ethnic group mirrors the ethnic make-up of the population of all ages (Online table 10.4). However, the older population has a higher proportion of White British than the population of all ages. Figure 1.12 uses experimental statistics to show the percentages of the population aged 50 and over who consider themselves to belong to any other ethnic group than White British. London had a significantly larger percentage of people in all other ethnic groups (31 per cent) than the other regions of England, although this was a lower percentage than for the population as a whole (42 per cent). About 10 per cent of the West Midlands older population was of other ethnicities than White British, compared with 17 per cent of the region's total population. This was the only other region where the proportion of the older population that was not White British was above the England average of 9 per cent. The North East (3 per cent) and the South West (4 per cent) had the lowest percentages ( 6 and 8 per cent respectively for all ages).

\section{Figure 1.12}

Population aged 50 and over who are not White British, England, 2007

Percentages

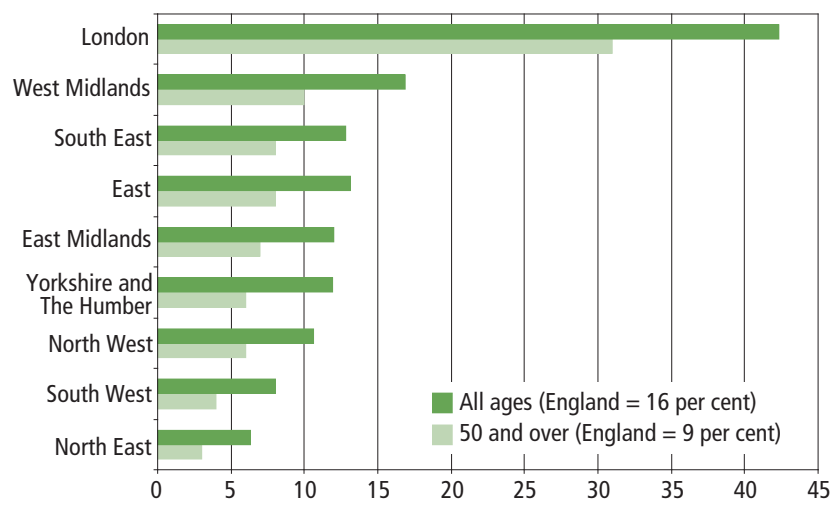

Source: Office for National Statistics, Experimental Statistics 


\section{Poverty and deprivation}

There are regional variations in the proportion of over 60 s who live on low incomes, and even greater differences at small area level. A number of measures of poverty are available at regional level, including household income and benefit receipt (Box 3 ) and the regional patterns vary according to which measure is used. Regional and also rural/urban differences mask variations in deprivation at small area level, which are explored using the Income Deprivation Affecting Older People Index, which is part of the Indices of Deprivation.

\section{Households Below Average Income}

Households Below Average Income is a standard measure of poverty that is available at region and country level across the
UK. At this geographic level, data have to be averaged over three years. Figure 1.13 illustrates the percentage of people aged 60 and over living in households where the household income was below 60 per cent of median household income (after housing costs) for 2005/06 to 2007/08. The highest percentages were found in London, the East Midlands and Northern Ireland (22 per cent, 21 per cent and 20 per cent respectively) compared with a UK average of 18 per cent. The lowest level of poverty on this measure was 16 per cent in the East of England, the South East and Scotland.

\section{Pension Credits}

Pension Credit data give another measure of poverty that is available across the whole of Great Britain (but not Northern Ireland). Pension Credits are available to people aged 60 and

\section{Box 3: Measures of poverty and deprivation in the ageing population}

Three currently available measures that enable assessment of the levels of poverty and income deprivation of the older population of the UK are detailed below.

\section{Households Below Average Income}

Households Below Average Income (HBAl) uses household disposable incomes, after adjusting for the household size and composition, as a proxy for material living standards. More precisely, it is a proxy for the level of consumption of goods and services that people could attain given the disposable income of the household in which they live. In order to allow comparisons of the living standards of different types of households, income is adjusted to take into account variations in the size and composition of the households in a process known as equivalisation, which is explained in more detail below. A key assumption made in HBAl is that all individuals in the household benefit equally from the combined income of the household. This enables the total equivalised income of the household to be used as a proxy for the standard of living of each household member.

This section includes results only for those individuals above state pension age. Thus, any working-age partners will be excluded from results for pensioner couples.

Statistics presented in this section have been equivalised by the Department of Work and Pensions (DWP) before publication in their annual report. Income is adjusted, or equivalised, to take into account variations in both the size and composition of the household. This reflects the idea that a family of several people needs a higher income than a single person in order for both households to enjoy a comparable standard of living. The reference point, conventionally, is a couple with no children.

\section{Pension Credits}

Pension Credit (PC) was introduced on 6 October 2003 and replaced the Minimum Income Guarantee (MIG). It is paid to people aged 60 and over who are living on low incomes and guarantees all pensioners a certain level of income. There are two parts to Pension Credit: the Guarantee Credit (GC) and the Savings Credit (SC). The Guarantee Credit ensures a guaranteed level of income by providing financial help for people aged 60 and over whose income is below a given threshold. The Savings Credit is an extra amount for people aged 65 or over who have made modest provision for their retirement above the level of the basic state pension (such as savings or a second pension). Entitlement to the Guarantee Credit and the Savings Credit is calculated separately, and as a result, pensioners can receive both or either elements of Pension Credit.

\section{Income Deprivation Affecting Older People Index}

The Income Deprivation Affecting Older People Index (IDAOPI) was developed by Communities and Local Government (CLG) as part of the Indices of Deprivation (see Understanding the Indices of Deprivation in Regional Trends 41). IDAOPI represents income deprivation affecting adults aged 60 and over living in pension credit (guarantee) households. This comprises claimants of Income Support, Job Seekers Allowance, Incapacity Benefit, Pension Credit or Council Tax Credit, and their partners (if also aged 60 or over). The IDAOPI score is the percentage of adults aged 60 and over living in such households as a percentage of all adults aged 60 and over. The index is not a National Statistic although the underlying data are.

IDAOPI is calculated at Lower Layer Super Output Area (LSOA) level. LSOAs are ranked on their IDAOPI score according to their position relative to all other LSOAs in England. They can be divided into 10 equal-sized groups (deciles), with decile 1 being the most deprived and 10 being the least deprived. 


\section{Figure 1.13}

\section{Percentage of people aged 60 and over in low- income households, ${ }^{1}$ 2005/06 to 2007/08}

Percentages

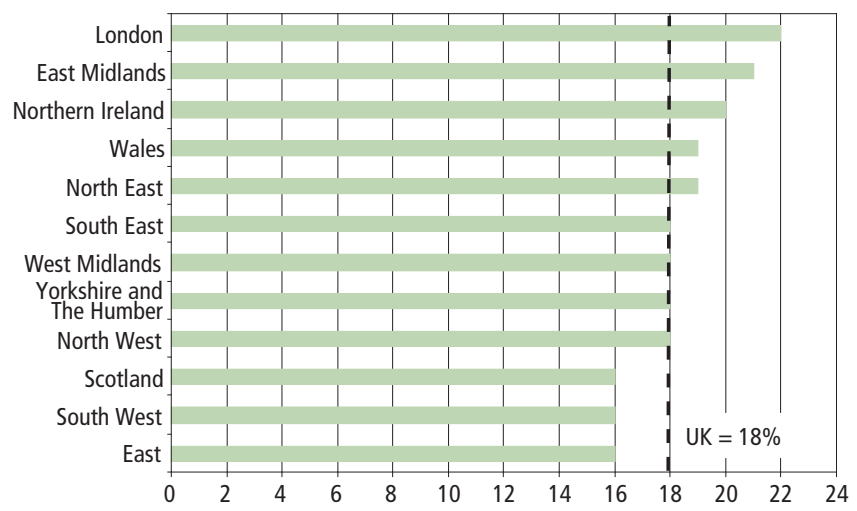

1 Households below 60 per cent of median income; after housing costs. See Notes and Definitions Online.

Source: Family Resources Survey, Department for Work and Pensions

over and guarantee a minimum income by topping up weekly income. Those receiving Pension Credit are also eligible for other benefits such as Council Tax Benefit. However, as a measure of low income, it has the disadvantage that take-up by those who are eligible is relatively low (estimated at between 61 and 70 per cent in 2007/08, and a little lower for pensioner couples compared with single pensioners (DWP, 2009)). Those who do not claim may suffer greater hardship than those receiving credits. Figure 1.14 illustrates the percentage of people aged 60 and over who were claiming Pension Credit at a regional level in 2008.

In 2008 approximately a quarter of the 60 and over population in Great Britain were either claiming Pension Credit or benefiting from it by being related to someone who did claim. The North East (33 per cent) had the highest percentage of the 60 and over population receiving this benefit, while the South East (18 per cent) had the lowest.

\section{Figure 1.14}

\section{Beneficiaries ${ }^{1}$ of Pension Credits as a percentage of population aged 60 and over, ${ }^{2} 2008$}

Percentages

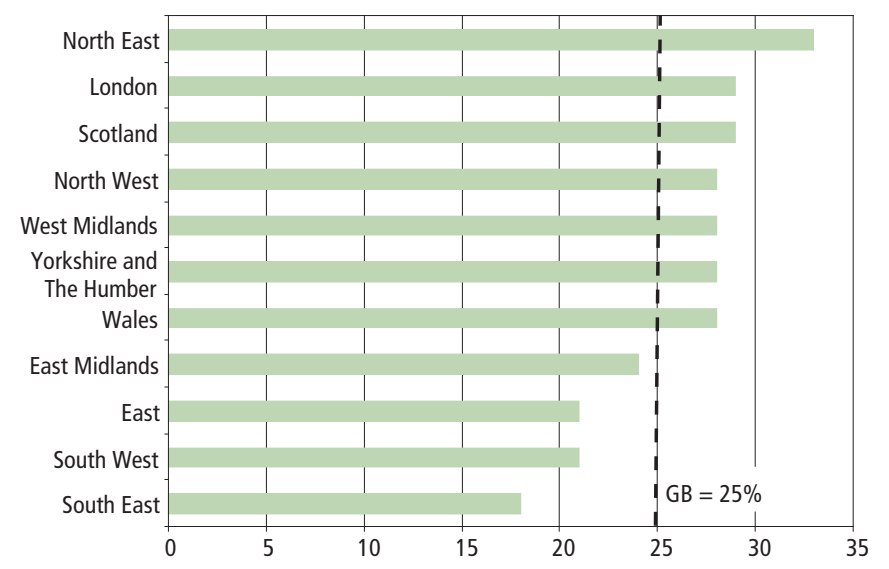

1 Beneficiaries are claimants and their partners for whom Pension Credit is received and are on the administrative system at the reference date.

2 Claimant partners who may be aged under 60.

Source: Department for Work and Pensions; Office for National Statistics
Income Deprivation Affecting Older People Index

The Income Deprivation Affecting Older People Index (IDAOPI) - part of Communities and Local Government's (CLG's) Indices of Deprivation - provides a measure of poverty for small areas. It is defined as those adults aged 60 and over living in Pension Credit (guarantee) households as a percentage of all those aged 60 and over (Box 3). This measure is available for Lower Layer Super Output Areas (LSOAs), which only apply to England. Northern Ireland has also produced a similar index measure - the Income Deprivation Affecting Older People (IDAOP) - as part of the Northern Ireland Multiple Deprivation Measure 2005 (NIMDM, 2005).

Figure 1.15 illustrates the percentage of adults aged 60 and over in 2008 living in the 10 per cent most deprived LSOAs in

\section{Figure 1.15}

\section{Population aged 60 and over in the 10 per cent most deprived LSOAs' ${ }^{1}$ in England, 2008}

Percentages

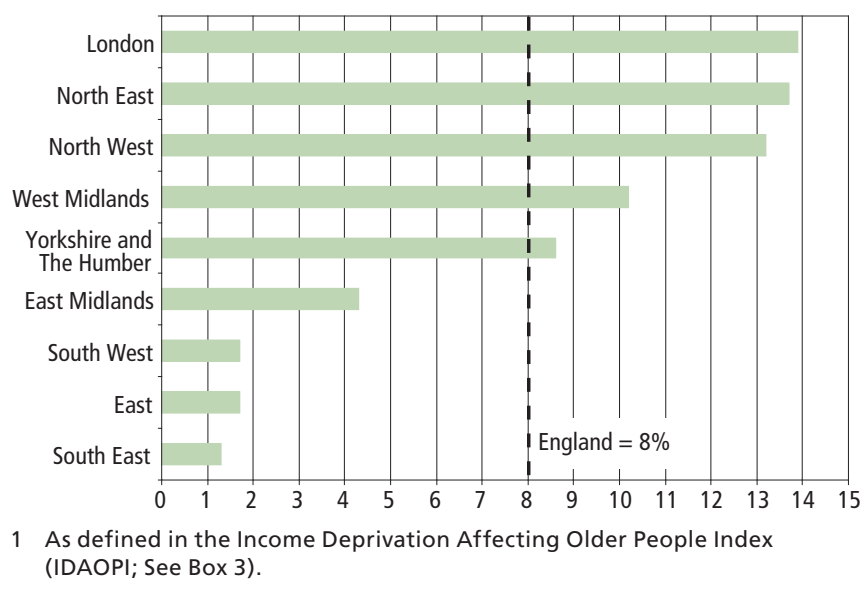

Source: Communities and Local Government; Office for National Statistics

each English region measured using IDAOPI. Except for London, which has the highest percentage at nearly 14 per cent, all the other regions above the England average of 8 per cent are found in the midlands or north of England (with the highest being the North East, also nearly 14 per cent and the North West, 13 per cent). The South East, the South West and the East of England were the lowest, each at between 1 and 2 per cent. Although the geographic distribution (that is, the order of regions) is broadly similar to that shown in Figure 1.14 - illustrating Pension Credit take-up - the variation is much more dramatic between the maximum and minimum values, as it focuses solely upon the 10 per cent most deprived areas. In 2008 less than 800,000 people aged 60 and over lived in the 10 per cent most deprived LSOAs compared with 1.4 million people in the 10 per cent least deprived LSOAs.

Older people in deprived areas by the Rural/Urban Definition

Just over 8.6 million people aged 60 and over lived in urban areas (with a population over 10,000), with a further 
Figure 1.16

Population aged 60 and over: by IDAOPI' decile and Rural/Urban Definition, ${ }^{2}$ England, 2008

Thousands

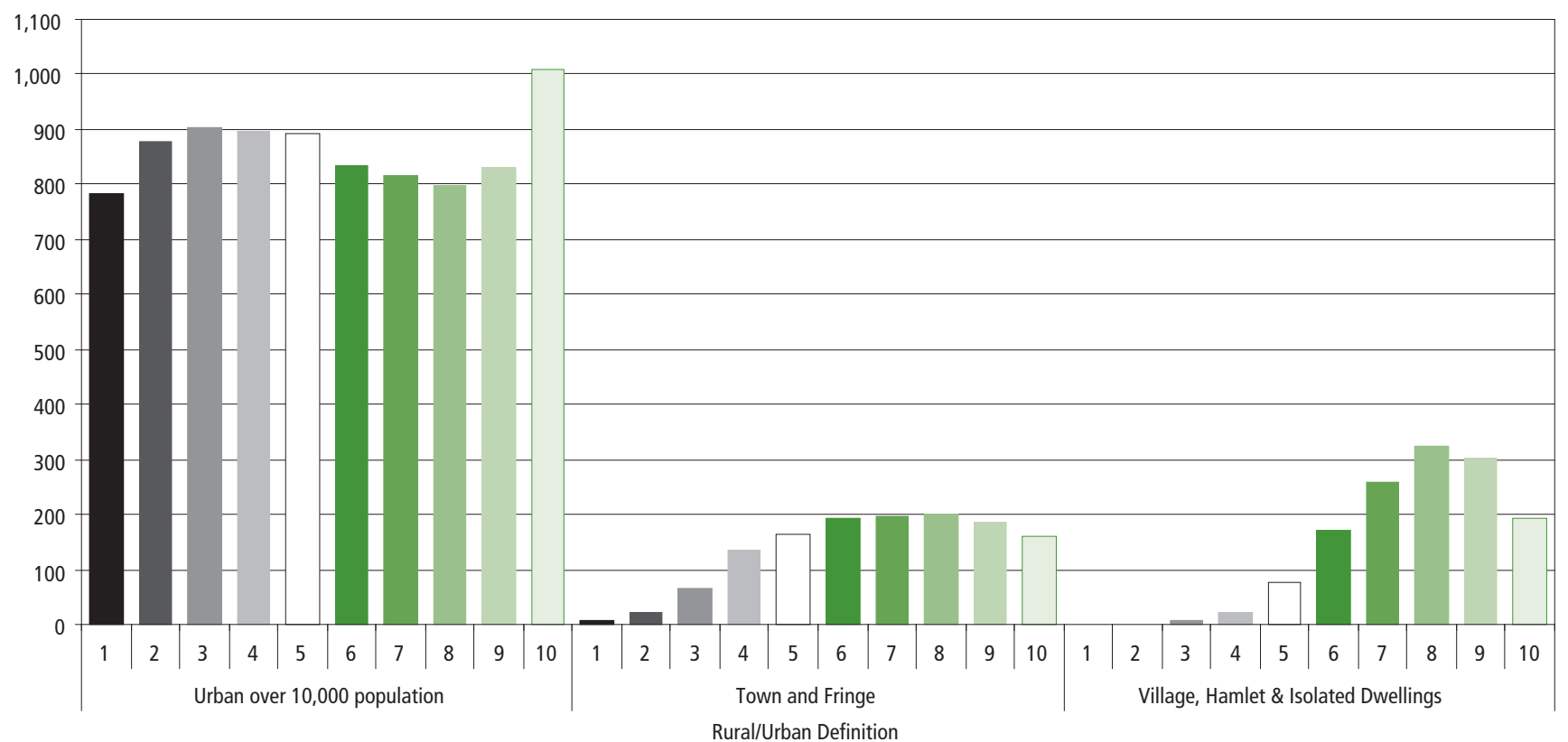

1 Income Deprivation Affecting Older People Index. See Box 3. Decile 1 (bottom 10 per cent of IDAOPI) is 'most deprived'; Decile 10 (top 10 per cent of IDAOPI) is 'least deprived'.

2 Categorised at Lower Layer Super Output Area level.

Source: Communities and Local Government; Office for National Statistics

1.3 million living in town and fringe areas, and the remaining 1.4 million of this demographic group living in villages, hamlets and isolated dwellings. Figure 1.16 compares the distribution of the population aged 60 and over by IDAOPI for these main settlement types in the Rural/Urban Definition for England.

Those living in town and fringe or the most rural areas were more likely to live in the less deprived LSOAs than the more deprived areas. Urban areas exhibited a more uniform spread, although a relatively high percentage of the older population was found in the least deprived decile (12 per cent). This is the outcome of a wide variety of distributions of deprivation across the regions. In areas deemed 'Town and Fringe' and 'Village, Hamlet and Isolated Dwelling' the distribution of the older population across the 10 deciles of IDAOPI was similar in all regions of England.

Figure 1.17 shows the different regional distributions of the 60 and over population by the IDAOPI deciles, in areas defined as 'Urban over 10,000 [population]' of the Rural/ Urban Definition.

It shows that the South East had a different distribution of deprivation levels from the other eight regions. The urban LSOAs in the South East that appeared in the least deprived 10 per cent of LSOAs in England included 18 times more people aged 60 and over than the urban LSOAs in the region that were among England's 10 per cent most deprived areas. This pattern is reflected in the high percentage of the population found in urban least-deprived areas shown in Figure 1.16 .
Like the South East, the South West, the East Midlands and the East of England show relatively small percentages of their older urban population living in the more deprived areas However, unlike the South East, each of these regions shows a levelling off or reduction in the proportions that are in the two or three least deprived deciles.

In contrast, London, the North East and the North West had more of their older (urban) population living in LSOAs in the more deprived half of England's LSOAs than in the less deprived half.

The other regions - the West Midlands and Yorkshire and The Humber - had relatively uniform spreads of their age 60 and over urban populations across the IDAOPI distribution.

\section{Regional case studies}

Maps 1.18 and 1.19 illustrate the geographical distribution, at LSOA level, of the areas of highest and lowest deprivation among the older population, for the North West and the South East respectively. These maps each highlight the LSOAS present within the top and bottom 10 per cent of IDAOPI and are selected to illustrate the variation in geographic distribution of the extremes of older people deprivation.

The North West exhibited a broad spread across the deprivation deciles of IDAOPI. Each decile contained between 9 and 13 per cent of the North West's population aged 60 and over. There was an approximately equal split between the five most and five least deprived deciles; 796,000 people 


\section{Figure 1.17}

Urban' ${ }^{1}$ population aged 60 and over: by IDAOPI decile ${ }^{2}$ by region of England, 2008

Percentages
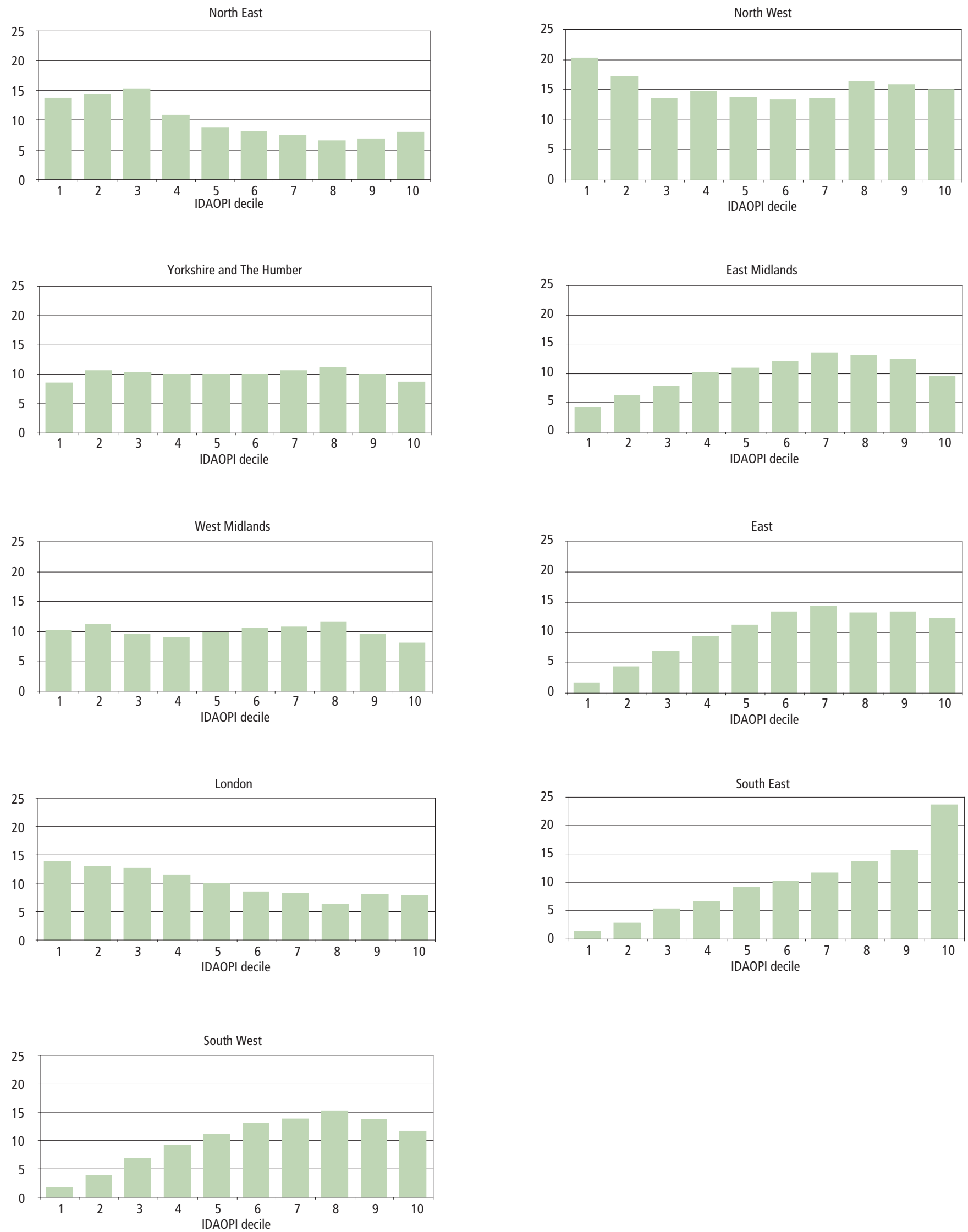

1 Urban over 10,000 population according to the Rural/Urban Definition. Categorised at Lower Layer Super Output Area level.

2 Income Deprivation Affecting Older People Index. See Box 3. Decile 1 (bottom 10 per cent of IDAOPI) is 'most deprived'; decile 10 (top 10 per cent of IDAOPI) is 'least deprived'. 
Map 1.18 The 10 per cent most and least deprived LSOAs, ${ }^{1}$ North West, 2007

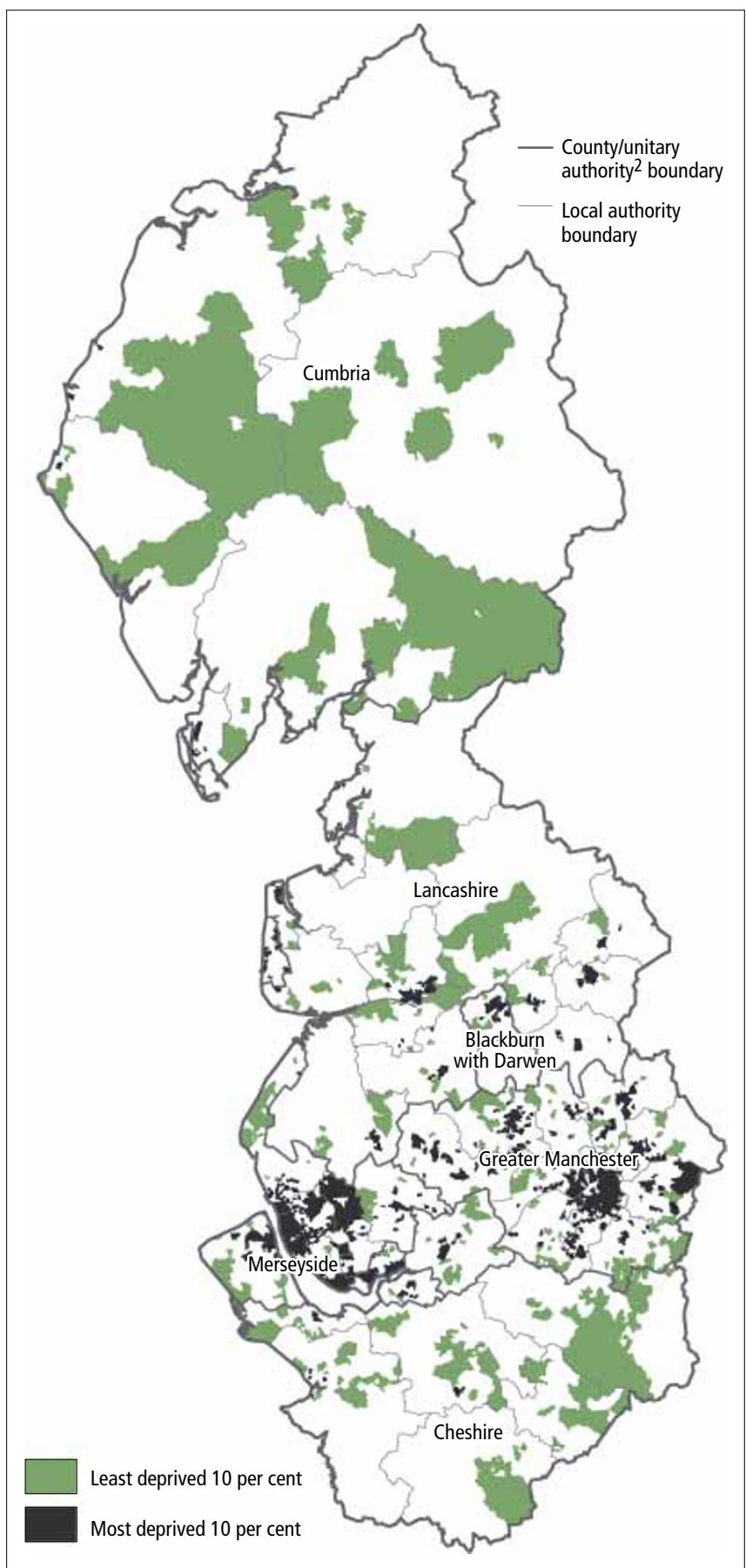

1 Most or least deprived in England according to the Income Deprivation Affecting Older People Index. See Box 3.

2 Unitary authorities not labelled: Blackpool, Halton and Warrington. Source: Communities and Local Government, Office for National Statistics

aged 60 or over lived in the five most deprived LSOA deciles, compared with 744,000 in the five least deprived deciles.

However, about one-third more people aged 60 and over lived in the most deprived 10 per cent of LSOAs in England than in the least deprived 10 per cent (203,000 compared with 150,000). The least deprived decile contained under half the number of LSOAs compared with the most deprived decile (8 per cent and 17 per cent respectively).
Map 1.18 shows that the North West's LSOAs in the least deprived decile of IDAOPI were roughly evenly spread throughout the region. The most deprived LSOAs, however, were more concentrated in inner city Liverpool and Manchester, and also Blackburn and Preston. They were also scattered through outer areas of the conurbations and some coastal areas. The least deprived LSOAs were located in the suburban and rural areas surrounding these cities, and large portions of the Lake District National Park, Cumbria and rural Cheshire.

Map 1.19 illustrates the South East region, which contained the largest percentage of the UK's 60 and over population of any region in 2008, at 17 per cent (1.9 million people). As the South East is the most affluent region in England (see article 'Understanding income at small area level' on pages 80 to 94), it is perhaps unsurprising that a very large percentage of this region's population aged 60 and over (75 per cent or 1.4 million) and LSOAs (70 per cent or 3,725) were found in the five least deprived deciles (as illustrated in Figure 1.17). This compares with nearly 0.5 million people and 1,594 LSOAs in the five most deprived deciles.

The stark contrast between most and least deprived areas in the South East is highlighted further when comparing only the most and least deprived deciles. Nearly 0.5 million (24 per cent) of the region's population and 1,129 (21 per cent) of the LSOAs were found in the least deprived decile, compared with just over 1 per cent $(25,000)$ of the population and 91 (2 per cent) of the LSOAs in the most deprived decile.

The least deprived LSOAs were geographically distributed across the entire region, although none were present on the Isle of Wight, and few were found east of Maidstone in Kent, or in the west of the region. The small numbers of most deprived LSOAs were located in small pockets throughout the region, mainly in inner city areas of Southampton and Portsmouth, and towns such as Brighton, Margate, Ramsgate, Gravesend, Rochester, Reading and Milton Keynes.

This case study analysis showed that the South East had a small proportion of its older population living in deprived areas, but these areas were concentrated in certain urban areas, both on the coast and in large inland towns. In contrast, the North West had a larger proportion of its older population living in more deprived areas. The most deprived areas, while more widespread than in the South East, were also located mostly in inner city areas, other large towns and in towns on the coast.

\section{Fuel poverty}

Income deprivation also contributes to fuel poverty. Being in fuel poverty means being unable to afford to keep warm. A household - not specifically the pensioner - is considered to be in fuel poverty if 10 per cent or more of its income is spent on fuel for adequate heating (usually 21 degrees Celsius for the main living area, and 18 degrees for other occupied rooms).

Living in cold homes can damage people's health and affect their quality of life. The elderly and those with a disability or long-term illness are among the population subgroups that are especially vulnerable. 


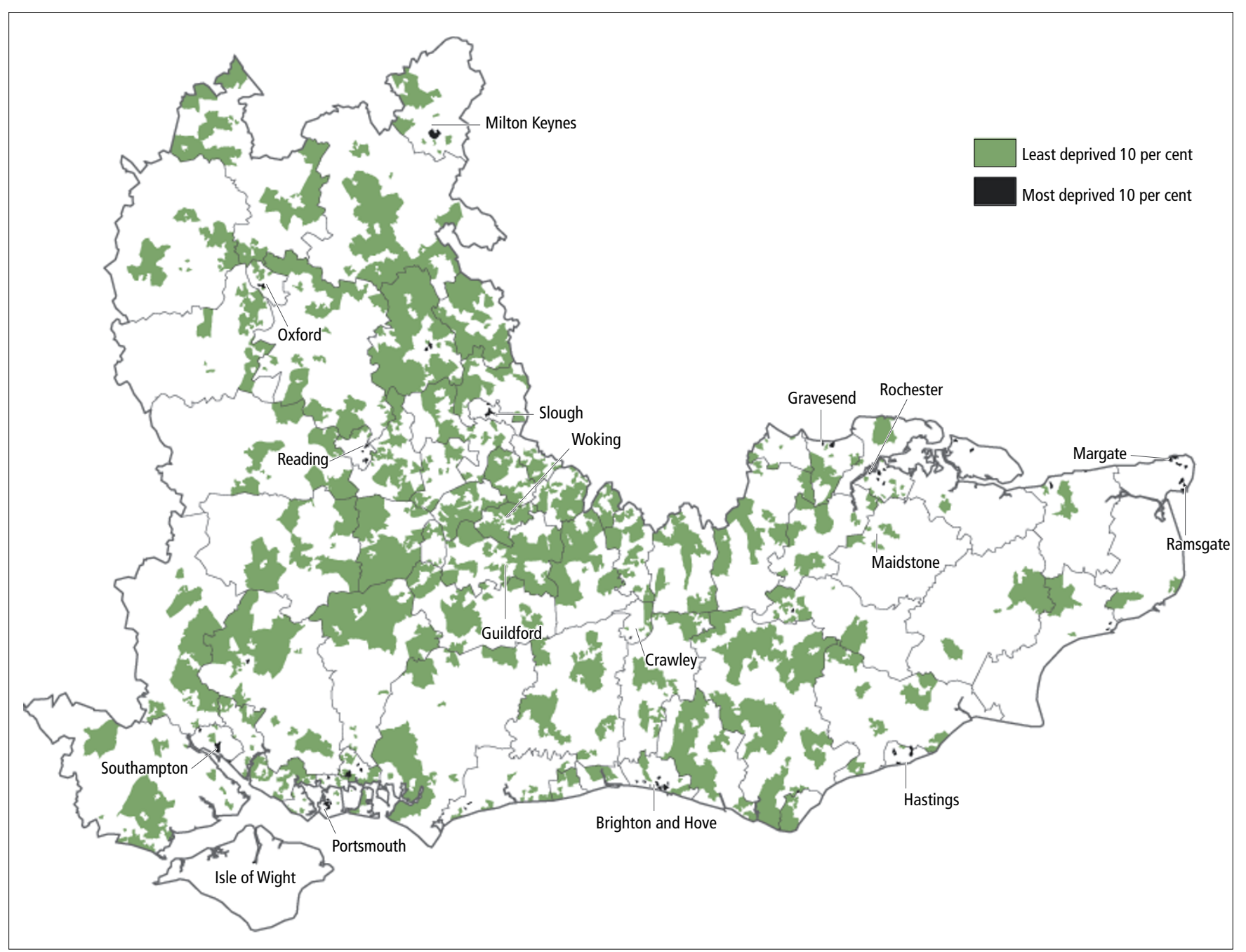

1 Most or least deprived in England according to the Income Deprivation Affecting Older People Index. See Box 3.

Source: Communities and Local Government, Office for National Statistics

There are three main causes of fuel poverty:

- Poor energy efficiency in the home

- High energy prices

- Low household income

The Department of Energy and Climate Change (DECC) produces annual statistics (which are not National Statistics) for England detailing the number of households considered to be in fuel poverty. Figure 1.20 illustrates these statistics for 2007 with respect to the number of households with at least one adult aged 60 and over living within it, as a percentage of all households of this type.

These data show there is an obvious geographic pattern to where people aged 60 and over are most likely to be living in fuel poverty. All northern and midland regions of England are above the English average of 18 per cent. The North East (24 per cent), the West Midlands (23 per cent) and Yorkshire and The Humber (22 per cent) had the highest percentages in 2007.
Figure 1.20

Percentage of households with one or more persons aged 60 or over in fuel poverty, ${ }^{1}$ England, 2007

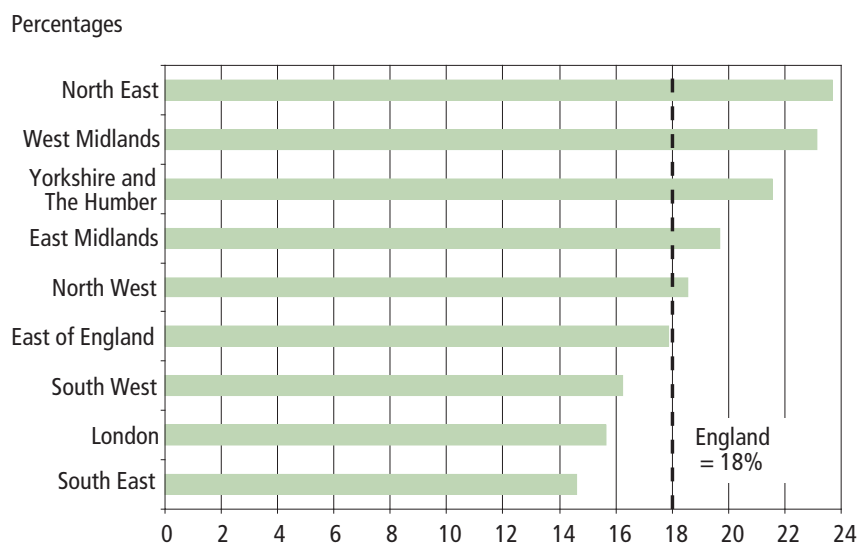

1 Not a National Statistic.

Source: English Housing Survey; Department of Energy and Climate Change 
More southerly regions exhibited lower percentages of households in fuel poverty containing one or more persons aged 60 and over. The South East had the lowest percentage 16 per cent.

\section{Health}

While life expectancy has increased, the extra years are not necessarily lived in good health. Well-established health care provision for older people includes vaccination against influenza, breast and cervical cancer screening, and hip and knee replacements. Other data are not available readily by age group or at regional level.

\section{Life expectancy}

Life expectancy (LE) estimates the average expected lifespan, in this case, that remains at age 65. Healthy life expectancy (HLE) divides the total LE into years spent in good and 'not good' health; disability-free life expectancy (DFLE) divides LE into years lived with and without a chronic illness or disability.

Figure 1.21 compares estimates of life expectancy, health life expectancy and disability-free life expectancy at age 65 by sex and UK country in 2004-2006. (Although 2006-08 life expectancy statistics are currently available, DFLE and HLE statistics will only be available towards the end of 2010, preventing them from being illustrated together in

Figure 1.21). Women were consistently estimated to have longer life expectancies - of all forms - than men in all countries of the UK between 2004 and 2006, with the exception of DFLE in Northern Ireland. On average in the UK, women at age 65 were expected to live for approximately another 20 years, three years more than men. Lowest estimates for both sexes were in Scotland, while England had the highest values for both sexes.

People at age 65 were expected to have an average of 13 years of healthy life ahead of them, but the gap between women and men dropped to less than 2 years. The largest difference was 2 years in Scotland.

The UK average was further reduced to about 10 years for DFLE regardless of the sex in 2004-2006, with Northern Ireland exhibiting the lowest values at individual country level for both men (9.1 years) and women (9.0 years). England and Scotland showed the highest single country levels for DFLE, at 10.7 years for women.

More recent estimates of total life expectancy (LE) at age 65 are, however, available for lower UK geographies. Map 1.22 illustrates life expectancy at age 65 by sex at local authority level across the UK in 2005-2007. The majority of LADs exhibit differences in life expectancy between men and women close to the UK average. However, 25 LADs had female life expectancies at least 3.5 years greater than men. These are spread geographically across the UK. In six local authorities, the male/female difference was 1.5 years or less.

\section{Figure 1.21}

Life expectancy, healthy life expectancy and disability-free life expectancy at age 65: by sex and UK country, 2004 to 2006

Years

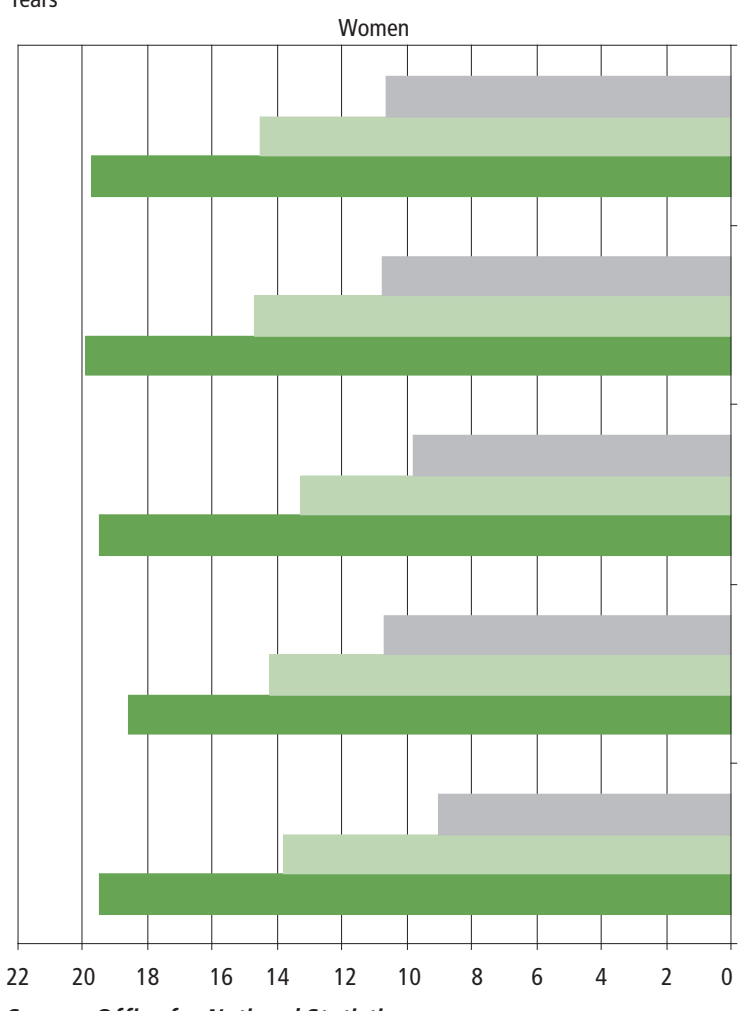

UK

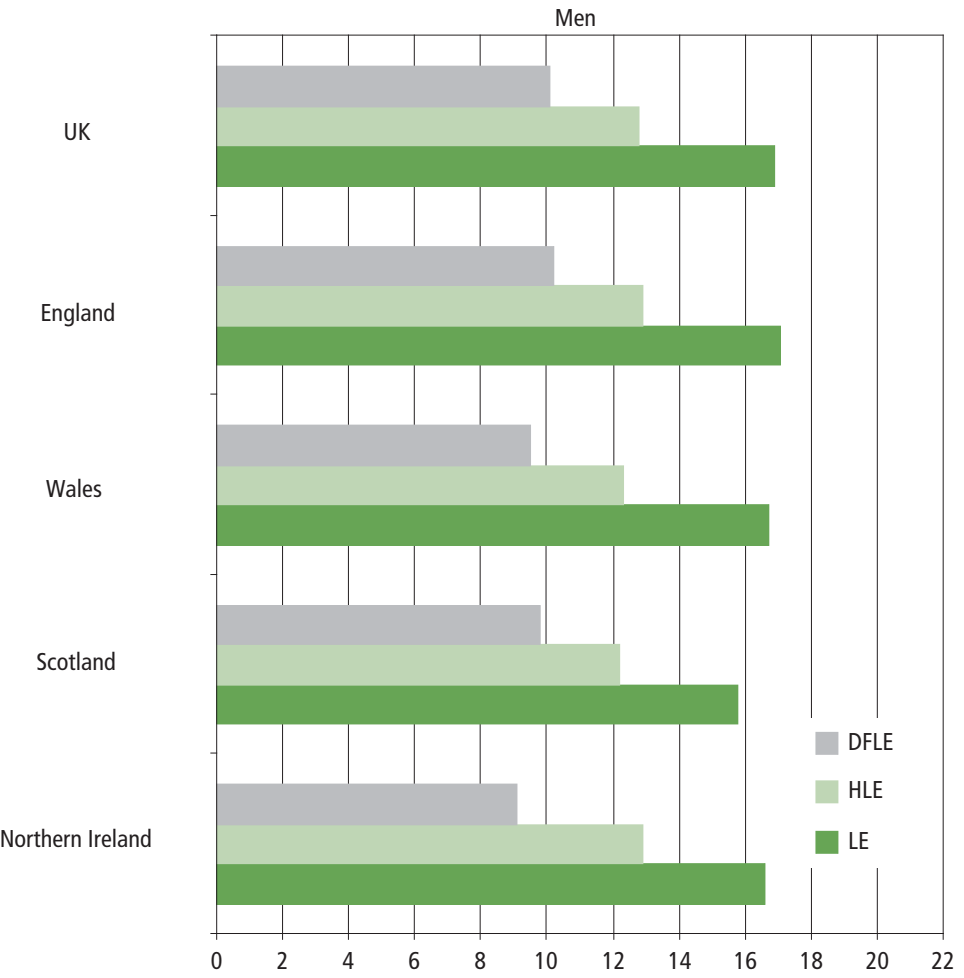

Source: Office for National Statistics 

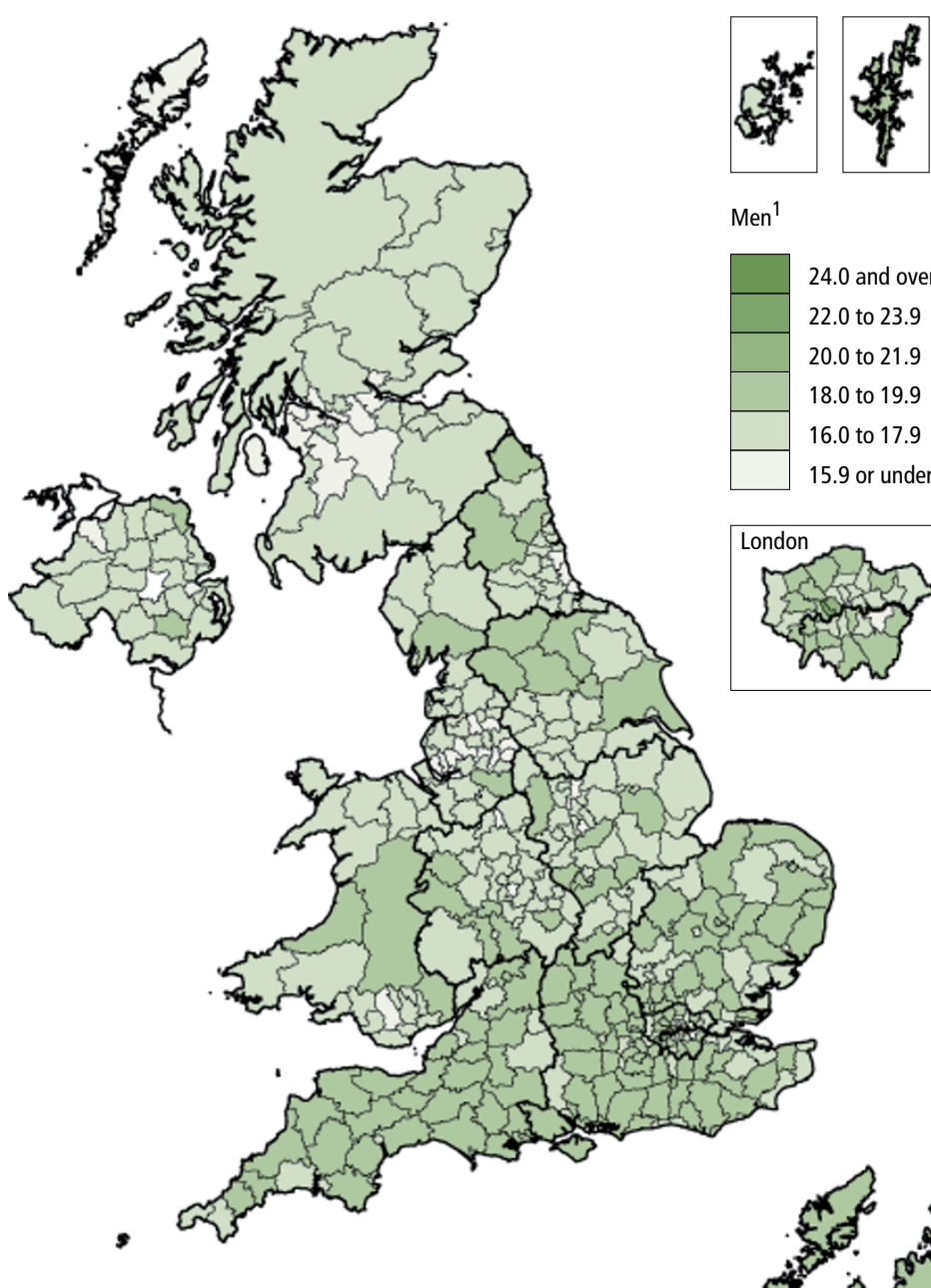

24.0 and over

22.0 to 23.9

20.0 to 21.9

18.0 to 19.9

16.0 to 17.9

15.9 or under
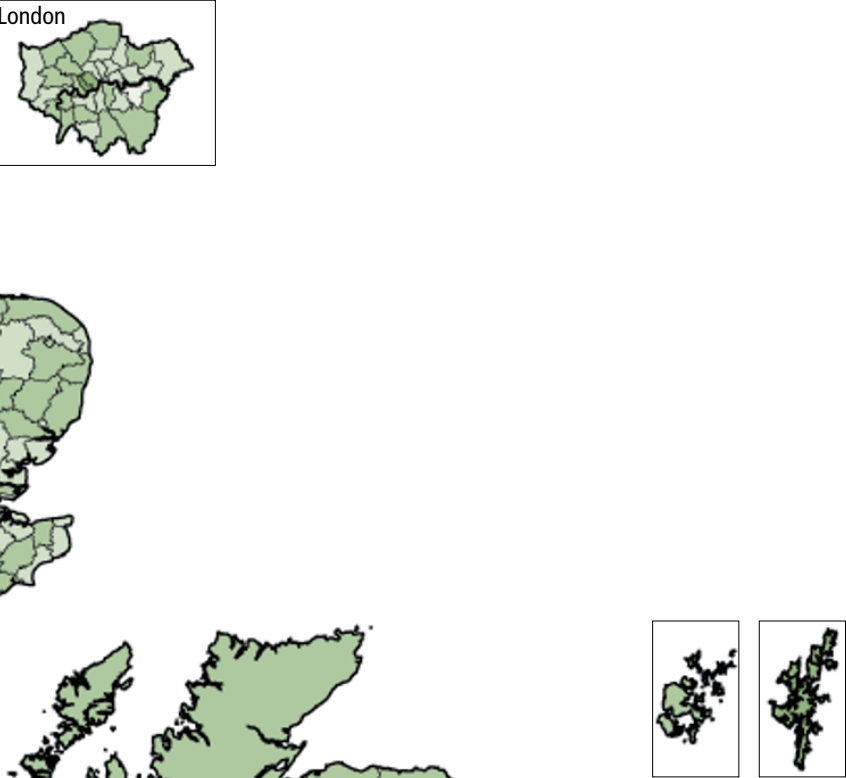

Women ${ }^{1}$

24.0 and over 22.0 to 23.9

20.0 to 21.9

18.0 to 19.9

16.0 to 17.9

15.9 or under
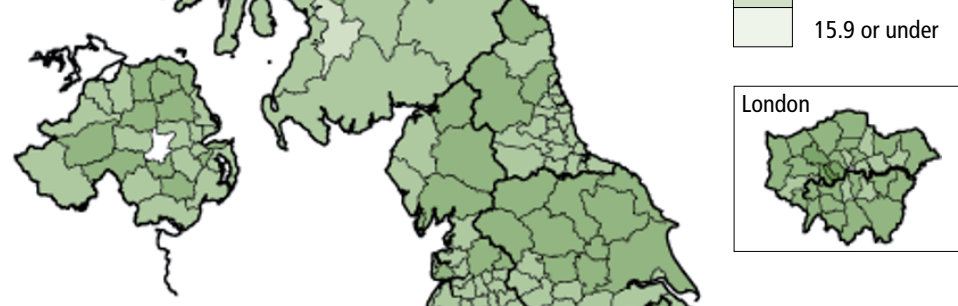

1 No data available for City of London and Isles of Scilly. 
Among men, the local authority districts with the highest LE at age 65 were Kensington and Chelsea (22.7 years), Westminster (21.2 years) and Crawley (20.3 years). In a further 24 LADs, men at age 65 had between 19 and 20 years of life expectancy, with the majority located in the South East, and none further north than Rutland and Leicester in the East Midlands. This trend was also seen in LADs in the East of England, Wales, the West Midlands and the South West. The local authorities with the lowest life expectancy at age 65 for men were Glasgow City (13.9 years) and North Lanarkshire (14.9 years), while Manchester, Hartlepool and Liverpool had the lowest in England, all at 15.5 years for men.

In more than half of all local authorities in the UK (255 out of 434), women at age 65 were expected to live, on average, another 20 or more years. The highest life expectancy at age 65 for women was seen in Kensington and Chelsea at 25.2 years. Life expectancy for women at age 65 was also high in Rutland, East Dorset (both 22.7 years) and Westminster (22.6 years).

Only three local authorities had life expectancies of over 20 years for both men and women (Kensington and Chelsea, 22.7 years and 25.2 years; Westminster, 21.2 years for men and 22.6 years for women; and Crawley, 20.3 years and 21.1 years).

\section{Figure 1.23}

\section{Breast $^{1}$ and cervical ${ }^{2}$ cancer screening: by country and strategic health authority, 31 March 2008}

Percentages

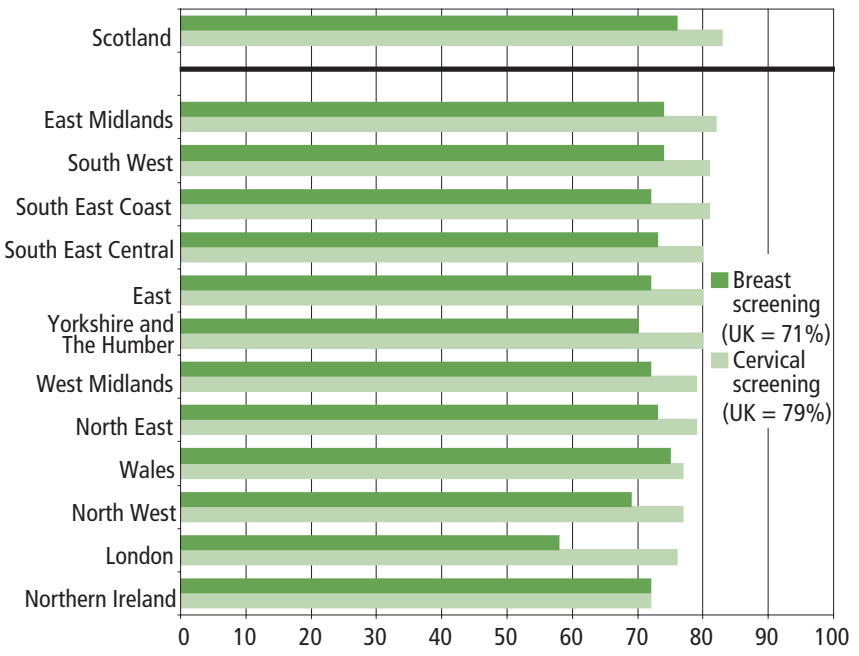

1 Percentage of target population aged 50 to 64 screened in the previous three years. See Online Notes and Definitions.

2 Percentage of women aged 50 to 64 years screened in the previous five years. For Scotland, women aged 55 to 59 screened in the previous five and a half years. See Online Notes and Definitions.

Source: Office for National Statistics; Department of Health; Welsh Assembly Government; General Register Office for Scotland; Information and Statistics Division, NHS Scotland; Northern Ireland Statistics and Research Agency; Department of Health, Social Services and Public Safety, Northern Ireland

\section{Breast and cervical cancer screening}

Cervical and breast cancer may be treated successfully in a suitable treatment programme if identified early enough by screening programmes. Generally, breast screening programmes target the 50 and over female population, while cervical screening programmes target a wider age range, down to 25 years of age. Figure 1.23 (Online table 6.7) presents the percentages of women aged 50-64 who had been screened for cervical and breast cancer in the period before March 2008 by the English strategic health authorities (SHAs), Wales and Northern Ireland.

In the three years before March 2008 an average of 71 per cent of women aged 50-64 across the whole of the UK attended a breast cancer screening. Women of this age in Scotland had the highest participation in breast cancer screening (76 per cent). London had the lowest percentage participation in the breast screen programme, at 58 per cent. This is well below the next lowest percentage seen among women of this age group in the North West (69 per cent). All other countries and regions of the UK had coverage of 70 per cent or greater.

In England, 79 per cent of women aged 50-64 participated in cervical cancer screening in the five years before March 2008. The percentage of women of this age participating in cervical cancer screening was highest in the East Midlands, the South West and the South East Coast SHAs, all with over 80 per cent participation. Of the countries for which comparable data are available, Northern Ireland had the lowest percentage of women of this age group (72 per cent) participating in the cervical cancer screening programme. Scotland has been excluded because the screening programme ends at age 59 .

\section{Figure 1.24}

Percentage of people aged 65 and over, immunised against influenza: by country and strategic health authority, 2007/08

Percentages

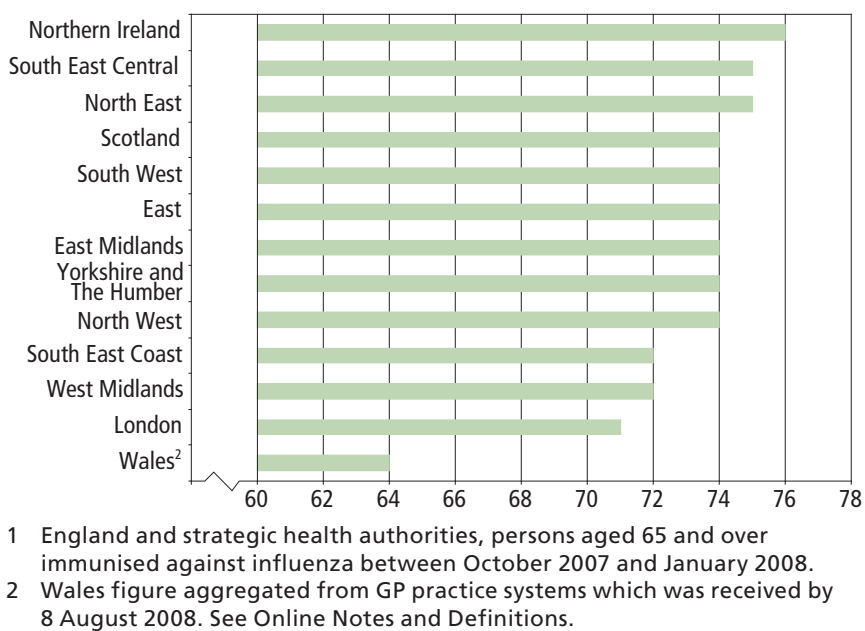

Source: Health Protection Agency, The NHS Information Centre for health and social care; Health Statistics and Analysis Unit, Welsh Assembly Government; Information Services Division (ISD) Scotland; Department of Health, Social Services, Northern Ireland 


\section{Flu vaccinations}

In recent years, the government has put great effort into providing older people with free influenza vaccinations. The highest flu vaccination uptake between October 2007 and January 2008 was in Northern Ireland (76 per cent of the people aged 65 and over) (Figure 1.24; Online table 6.7). A further five regions (the South West, the East, the East Midlands, Yorkshire and The Humber, and the North West) as well as Scotland had 74 per cent of their population aged 65 and over vaccinated against influenza. People aged 65 and over in Wales had the lowest percentage of vaccination take up, at 64 per cent.

Hip and knee replacements

Figure 1.25 presents rates per 10,000 population aged 65 and over for hip and knee replacements completed in England and Wales in 2008/09 using non-National Statistics data from Hospital Episode Statistics (HES). Of the English regions, the South West (173 per 10,000) had the highest rate, and was the only region with a level above 170 per 10,000 population, while London (118 per 10,000) had the lowest rate of completed admissions for these procedures.

\section{Figure 1.25}

\section{Rates of hip and knee replacements for 65 year-olds and over: by strategic health authority, 2008/09 \\ Rate per 10,000 people aged 65 and over}

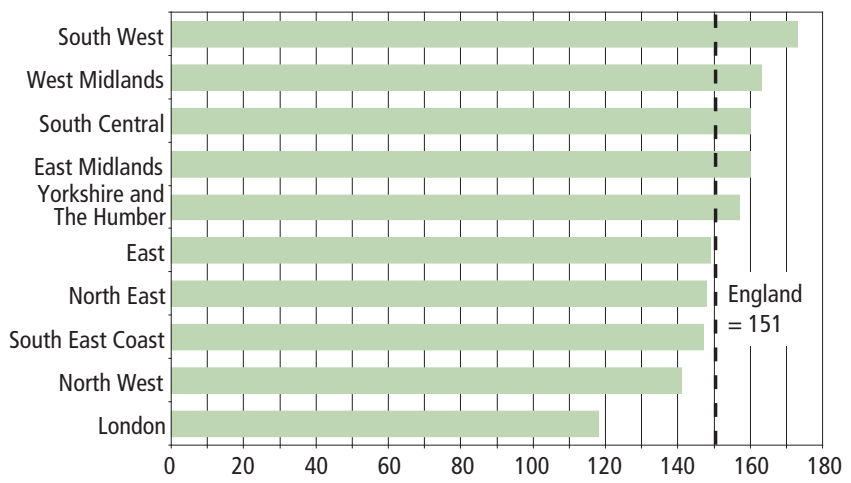

Source: The NHS Information Centre for health and social care; Office for National Statistics

\section{Social care}

The growing numbers of older people living to advanced years but with poor health increases the demand for social care. Some statistics are available on care organised or supported by local government social services departments to enable people aged 65 and over to live independently. However, this is likely to understate the total care provision since families may provide care themselves or pay for private care services. Many people with disabilities or needing some sort of care are entitled to government benefits such as Disability Living Allowance and Attendance Allowance. Some of the informal carers are themselves older people but they are identifiable only if they claim Carer's Allowance. Other old people are unable to live independently and move into residential care homes; these are not identified here.

\section{Care at home}

The government aims to achieve independence for older people through rehabilitation/intermediate care either in hospitals, care homes or private homes. One indicator (not National Statistics) in England is 'the percentage of older people aged 65 and over discharged from hospital to intermediate care/rehabilitation/re-ablement who are still living "at home" three months after the date of their discharge from hospital'.

Figure 1.26 presents this percentage for those discharged from hospital to intermediate care during the period 1 October to 31 December 2008 and who were still living at

Figure 1.26

Percentage of people aged 65 and over living at home after discharge from hospital,' 31 October 2008 to 31 December $2008^{2}$

Percentages

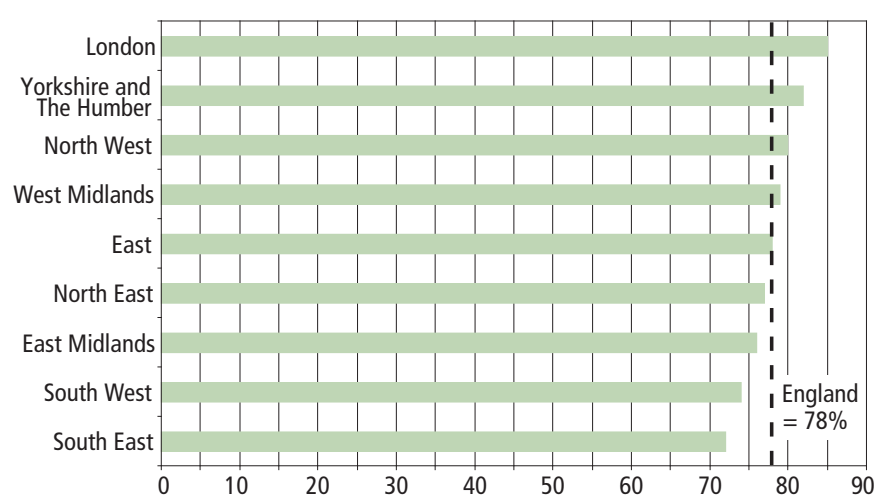

1 Who are still living 'at home' three months after the date of their discharge.

2 The collection of the denominator was for a three month period (1 October 2008 to 31 December 2008) with a three month follow-up for the numerator.

Source: The NHS Information Centre for health and social care

\section{Figure 1.27}

Rate of adults aged 65 and over assisted to live independently, 2008/091

Rate per 100,000 people aged 65 and over

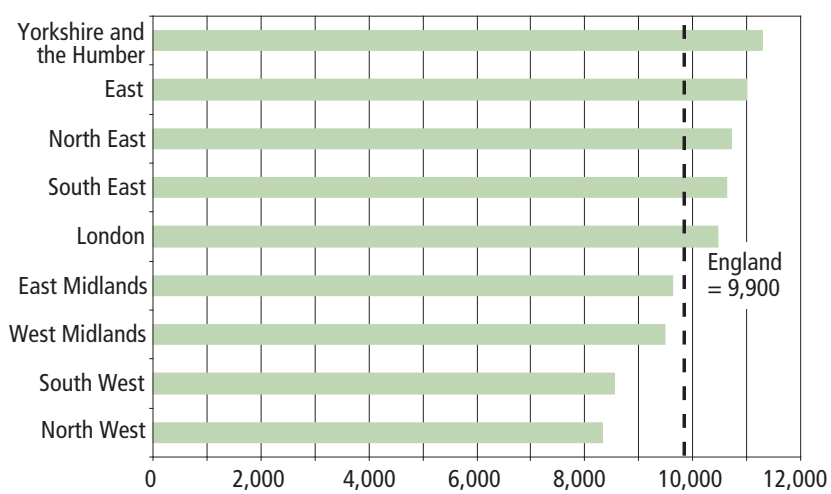

1 Provisional.

Source: The NHS Information Centre for health and social care 


\section{Figure 1.28}

\section{Percentage of people aged 60 and over receiving Disability Living Allowance, ${ }^{1} 2008$}

Percentages

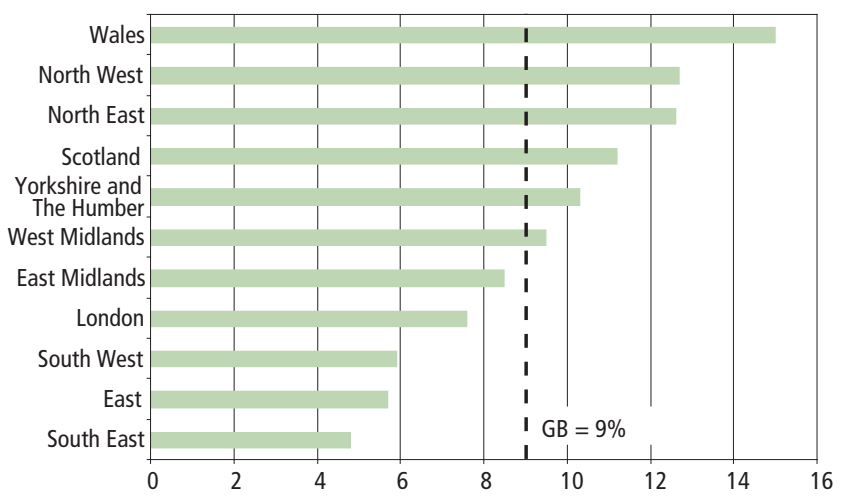

1 Disability Living Allowance is a tax-free benefit for those who need help with personal care or have walking difficulties because they are physically and/or mentally disabled, who were aged under 65 at the time of claiming Those aged 65 or over who are already receiving DLA may continue to receive it.

Source: Department for Work and Pensions; Office for National Statistics

home three months later. During this period in England, 78 per cent of people aged 65 and over were living at home three months after being discharged from hospital. London had the highest percentage of people aged 65 and over (85 per cent) living at home three months after being discharged from hospital. The South East had the lowest percentage at 72 per cent.

The NHS also monitors the levels and type of social care of people aged 65 and over. Figure 1.27 presents provisional estimates (not National Statistics) for the 'number of people aged 65 and over per 100,000 population [aged 65 and over] that are assisted directly through social services assessed/care planned, funded support to live independently, plus those supported through organisations that receive social services grant funded services'.

In England the rate of people aged 65 and over per 100,000 people (aged 65 and over) who were assisted through social services was 9,900 in 2008/09. Of all English regions, Yorkshire and The Humber and the East had the highest rate of people aged 65 and over who were assisted through social services (11,300 and 11,000 per 100,000 people aged 65 and over), while the North West $(8,300$ per 100,000$)$ and the South West $(8,500)$ had the lowest rates.

\section{Benefits and allowances}

A range of allowances are available to support people who need help because they are physically or mentally disabled, and also for those who care for them. The statistics give an indication of the number of people who have certain disabilities, need help with personal care, or who care for someone who is ill or disabled.

Disability Living Allowance (Figure 1.28) is a tax free benefit paid to people aged under 65 who have care or mobility needs as a result of a mental or physical disability. Those who are aged 65 or over may also be eligible to get Attendance Allowance. Wales (15 per cent) had the highest percentage of population aged 65 and over receiving DLA, compared with the Great Britain average of 9 per cent. The South East had the lowest take-up rate at 5 per cent, with the East and South West the next lowest at 6 per cent.

Attendance Allowance (Figure 1.29) is a tax-free benefit for people aged 65 and over who need help with personal care because they are physically or mentally disabled. They may get Attendance Allowance if they have a physical or mental disability (or both), and their disability is severe enough for them to need help caring for themselves. Again, Wales had the highest percentage of people aged 65 and over receiving this benefit (23 per cent), compared with the Great Britain average of 18 per cent. The South East had the lowest percentage of take-up of this benefit, at 15 per cent.

\section{Figure 1.29}

\section{Percentage of people aged 65 and over receiving Attendance Allowance, ${ }^{1} 2008$}

Percentages

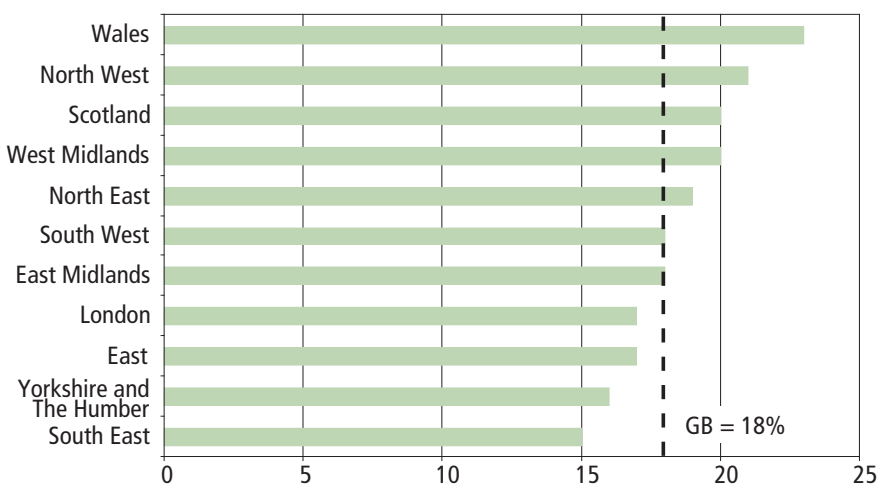

1 Statistics cover 'All entitled cases', so also incorporate those with entitlement but where the payment has been suspended, for example if they are in hospital.

Source: Department for Work and Pensions; Office for National Statistics

\section{Figure 1.30}

\section{Percentage of people aged 60 and over receiving} Carer's Allowance, ${ }^{1} 2008$

Percentages

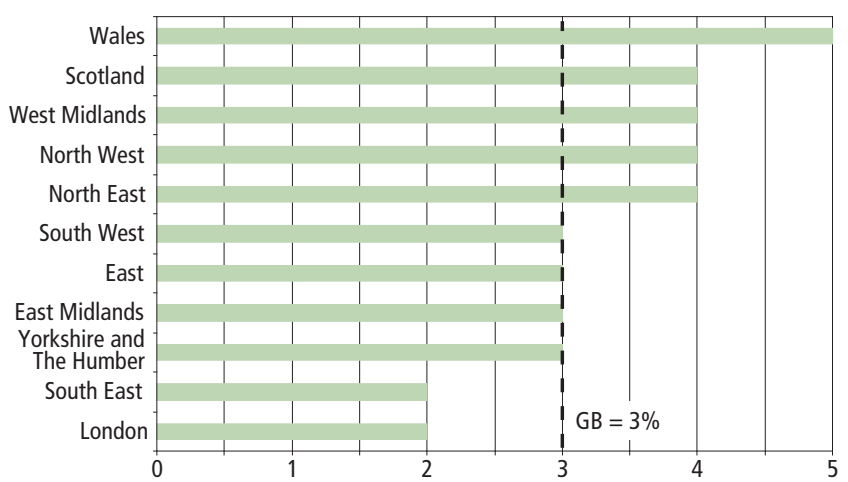

1 Statistics cover 'All entitled cases', so also incorporate those with entitlement but where the payment has been suspended, for example if they are in hospital. 


\section{Older carers}

Carer's Allowance (Figure 1.30) is available to those aged 16 and over who spend at least 35 hours per week caring for someone who is ill or disabled. Some of these are themselves older people. In 2008, 3 per cent of people aged 60 and over were claiming this benefit. Wales ( 5 per cent) had the highest percentage of claimants; the South East and London had the lowest at 2 per cent.

\section{Box 4: Workforce status}

Employed: The Labour Force Survey (LFS) definition of employment is consistent with the International Labour Organisation (ILO) definition, that is, anyone (aged 16 and over) who does at least one hour's paid work in the week prior to their LFS interview, or has a job that they are temporarily away from (for example on holiday). Also included are people who do unpaid work in a family business and people on government-supported employment training schemes. The employment rate is the number of people in employment as a percentage of the relevant population.

Unemployed (of the age group considered): Unemployment refers to people without a job who were available to start work in the two weeks following their LFS interview and who had either looked for work in the four

\section{Older workers}

Employment provides income and may provide a pension or allow personal pensions and savings to be built up for retirement. As health has improved more people wish to continue working beyond the long-established retirement ages. This has many benefits for those older people in work, and their skills and experience can be valuable to employers. The workforce generates national income which enables the

weeks prior to interview or were waiting to start a job they had already obtained. The unemployment rate is calculated as the number of economically active people who are unemployed as a percentage of the economically active relevant population (employed plus unemployed).

Economically inactive: The LFS definition of inactivity refers to people who are neither in employment nor unemployed. This includes those who want a job but have not been seeking work in the last four weeks, those who want a job and are seeking work but are not available to start work, and those who do not want a job. In the LFS, economic inactivity rate is given by the number of economically inactive people as a percentage of the relevant population.

\section{Figure 1.31}

Employment, unemployment and economic inactivity rates ${ }^{1}$ for people aged 50 to state pension age, 2008 Percentages

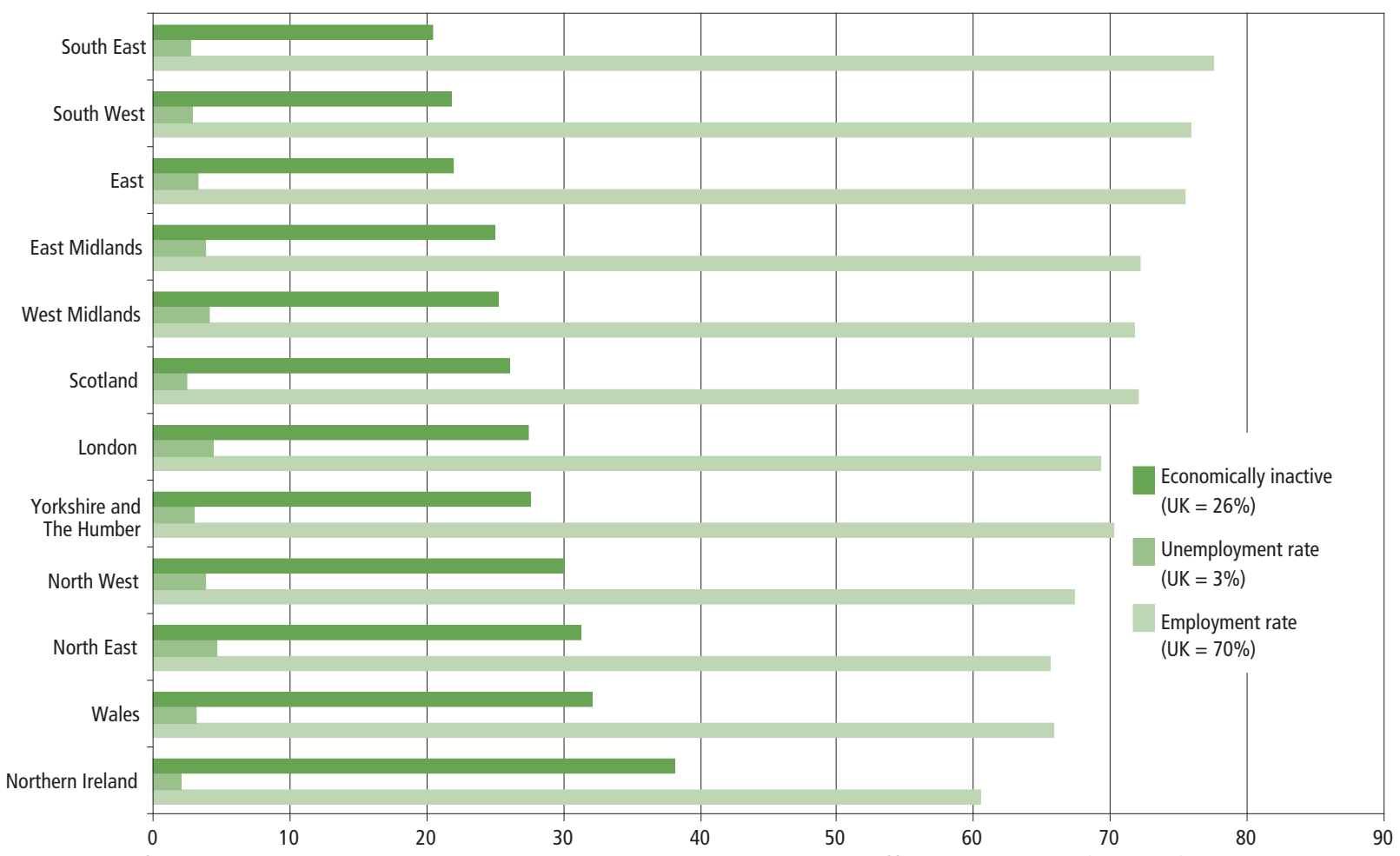

1 Percentages for each region will not add up to 100 per cent as unemployment rate uses a different denominator (see Box 4). 
provision of state welfare benefits. Government legislation has been passed to raise the age at which state pensions will be payable (Box 1) and enable greater flexibility for people to continue their careers longer.

People aged 16 and over are classed as employed, unemployed or economically inactive, and this is a reflection of their current status of participation in the workforce of the UK. Those aged 50 and over and who are in employment are usually defined as older workers.

Employment status of the workforce varies with age and sex. The shape and size of the workforce is determined by the inflows of younger workers balanced by older workers leaving through retirement or as a result of personal injury, disability or caring responsibility.

Nationally, England followed a general but expected trend for percentages of workforce among men and women to reduce with increasing age. Considering quinary (that is, five-year) age groups from age 50 to just above SPA, the percentage of men in employment (full and part-time combined) reduced from 84 per cent for those aged 50-54 to 23 per cent for those aged 65-69. Women showed a similar systematic withdrawal from the labour market with age, reducing from 76 per cent for those aged 50-54 to 13 per cent for the 65-69 age group. All regions also followed this same trend, except for men in London, where the percentage remaining in the labour force marginally increased between ages $50-54$ and $55-59$ by about 1 per cent. Although higher than a decade ago, the relatively small employment rates above SPA mean that reliable regional estimates are not available.

Figure 1.31 illustrates regional variation in the percentages of people aged 50 to SPA that are either in employment, unemployed or economically inactive (Box 4). These data from the Annual Population Survey (APS) (which is derived from the Labour Force Survey) show that higher employment rates are found in the southern regions of England, excluding London. The South East (78 per cent), the East and the South West (both 76 per cent) are the only regions above the UK average of 72 per cent for the percentage of the population aged 50 to SPA in employment. Northern Ireland has the lowest percentage at 61 per cent, with the North East and Wales the next lowest at 66 per cent each.

The pattern of unemployment - the percentage of the economically active population who are out of work and actively looking for work - shows higher proportions in the north of England, the midlands and London. Averaged over 2008, the North East and London had the highest unemployment rates for the 50 to SPA age group at 4.6 per cent and 4.4 per cent respectively. The lowest rate was in Northern Ireland (2.1 per cent).

A person is considered economically inactive if they are not working or seeking to work: for example because they are retired, looking after a home or family, permanently unable to work, sick or disabled or for other reasons. Northern Ireland
Figure 1.32

Percentage of employed men and women aged 50 to state pension age that are in full- or parttime employment, 2008

Percentages

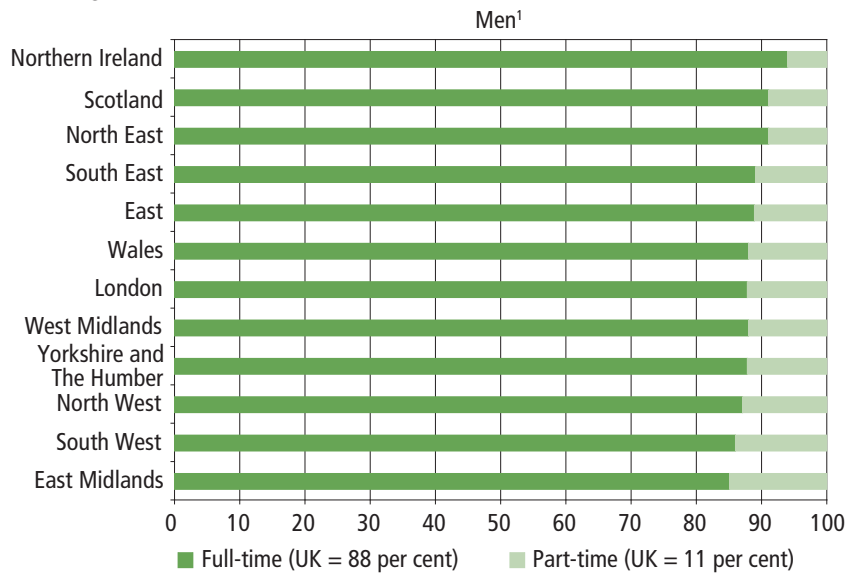

Women $^{2}$

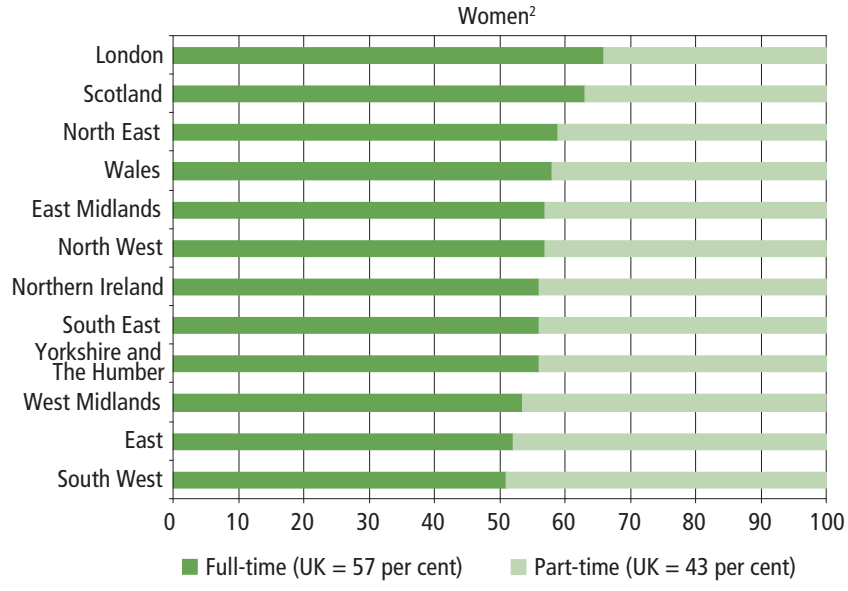

1 Denominator is all men in employment aged 50 to 64 .

2 Denominator is all women in employment aged 50 to 59.

Source: Office for National Statistics

(38 per cent), Wales (32 per cent), the North East (31 per cent) were the only countries and regions with over 30 per cent of their 50 to SPA population economically inactive, compared with the UK average of 26 per cent.

Figure 1.32 illustrates the percentage of men and women aged 50 to SPA in employment who worked full-time or part-time by English region and UK country in 2008. Different patterns are seen depending on whether sex or employment pattern is considered.

In all regions and countries of the UK in this age group, higher percentages of men worked full-time (UK 88 per cent) than women (57 per cent). Higher percentages of women work part-time (43 per cent) than men (11 per cent).

The highest percentages of men working full-time were found in Northern Ireland (93 per cent), Scotland (91 per cent) and the North East (91 per cent). London (66 per cent) and Scotland (63 per cent) had the highest percentage of women in this age group working full-time, and were the only areas having over 60 per cent of their female older workers working full-time. 
In the South West, the percentage of women who worked full-time in 2008 was comparable to those working part-time (51 per cent and 49 per cent respectively); the East also showed similar percentages (52 per cent and 48 per cent respectively).

\section{Quality of life}

Health and income are important factors affecting the quality of life enjoyed by older people. The English Longitudinal Study of Ageing provides an indicative, albeit subjective, measure of the quality of life using the CASP-19 scoring system. This defines wellbeing in terms of four domains:

- Control: the ability to intervene actively in one's own environment

- Autonomy: the right of an individual to be free from unwanted interference by others

- Self-realisation: the active processes of human fulfilment

- Pleasure: the sense of fun derived from the more active (doing) aspects of life

CASP-19 scores were based on answers given by respondents aged 55-85 to a series of 19 questions in the Health Survey for England. Average scores in 2006-07 progressively decreased after age 65 , indicating a reducing perception of wellbeing. This may be due to factors including poorer health in later life, loss of immediate family and friends and reduced mobility in older age. The sample size is insufficient to provide regional estimates.

The following sections show the information that is available at regional level on factors and activities that may affect the quality of life for older people.

\section{Housing tenure}

Home ownership provides a sense of security, autonomy and control over one's living arrangements, as well as being an indicator of wealth. In 2008 the majority of people aged 65 and over in the UK (71 per cent) owned their homes outright; 21 per cent rented their property; about 7 per cent owned their home with a mortgage/loan or part-rented/ part-owned; with around 1 per cent renting free or squatting.

Figure 1.33 presents housing tenure by UK country and English region with the categories of housing tenure described combined into two broad categories: home ownership (or part-ownership) and renting. In all regions and countries of the UK, at least two-thirds of people aged 65 and over owned their homes outright or with a mortgage; and for Wales, the South East and the South West regions, this proportion was over 80 per cent. The regions with the lowest levels of outright home ownership were the North East (68 per cent) and London (69 per cent).

\section{Education and skills}

One means of gaining self-realisation and pleasure is through learning and gaining qualifications. Qualifications gained

\section{Figure 1.33}

Housing tenure for people aged 65 and over, 2008

Percentages

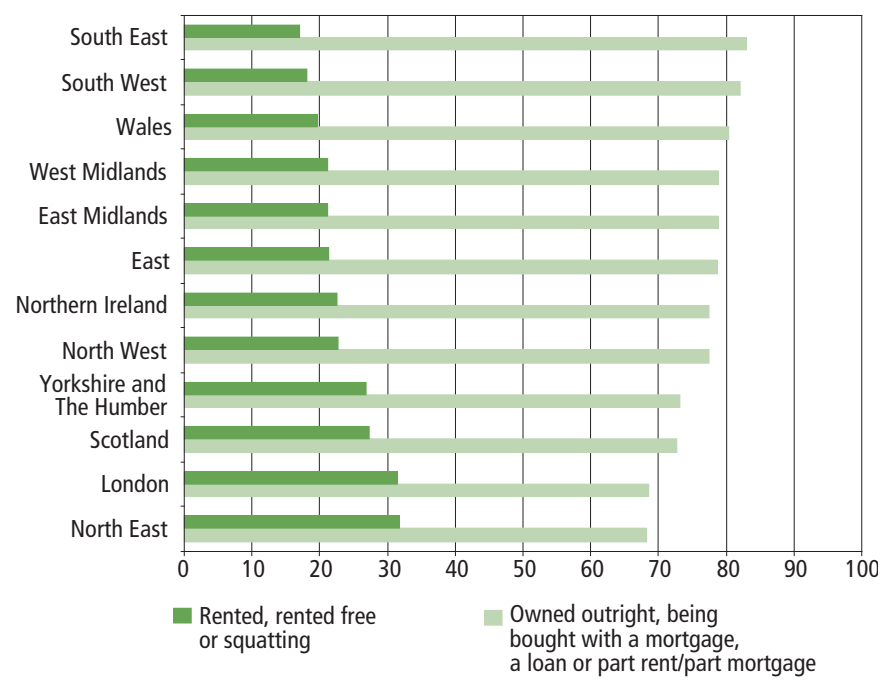

Source: Annual Population Survey, Office for National Statistics

through initial education and throughout working life are important for employment. As their children reach adulthood, people may participate in new activities outside work and others may undertake new activities after retirement. Some may undertake job-related learning to enable a career change.

Figure 1.34 shows the percentage of the UK's 50 to SPA population who had at least a National Qualification Framework (NQF) Level 4 qualification (Box 5) compared with those with no qualifications in the second quarter of 2009.

The highest percentages - those above the UK average of 29 per cent - of the population achieving a NQF Level 4 qualification were typically found in the south of England (the South East, 35 per cent; London, 34 per cent; the South West, 33 per cent). Lowest percentages were in Northern Ireland (22 per cent) and the North East (23 per cent).

Generally, those regions with the highest percentage of older people with a NQF Level 4 qualification were also those with the lowest percentages of people with no qualifications (the South East, 11 per cent, and the South West, 13 per cent).

\section{Box 5: National Qualification Framework (NQF)}

\section{Level 4 qualifications}

A Level 4 qualification in the UK is any one of the following certificates:

Teaching qualification (including PGCE); First Degree; BEC National HNC/HND; BTEC National HNC/HND; Higher Education Certificate; Higher Education Diploma; LCCI Advanced Level; NVQ Level 4; Nursing (SRN); RSA Advanced Certificate; RSA Higher Diploma. 
Figure 1.34

\section{Highest qualification level achieved for people aged 50 to state pension age, 2009 Q2}

Percentages

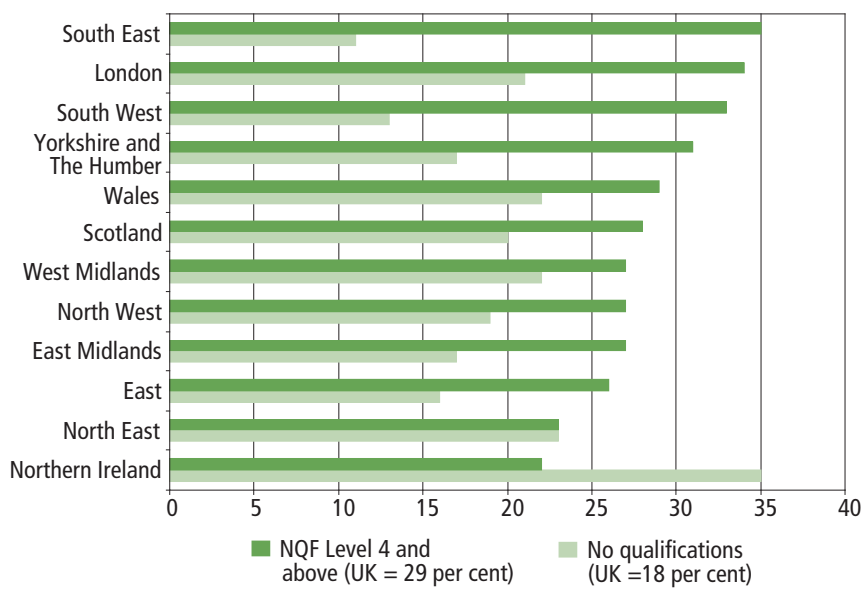

Source: Labour Force Survey, Office for National Statistics and Department for Business, Innovation and Skills

However, this pattern does not hold in London where a relatively high percentage had no qualifications. Similarly, areas with the lowest percentages achieving a NQF Level 4 qualification have the highest percentages with no qualifications; Northern Ireland (35 per cent) and the North East (23 per cent). However, similar levels to the North East were also found in the East Midlands (22 per cent), Wales (22 per cent) and London (21 per cent).

Qualification levels achieved have increased over time so it is interesting to compare the qualifications held by people aged 50 to SPA with those of the whole working-age population (aged 16-64 for men, 16-59 for women) (Online table 4.14). The largest difference at NQF Level 4 was only 5 percentage points in Scotland (33 per cent of working-age population; 28 per cent for those aged 50-SPA) and London (39 per cent; 34 per cent). However looking at those with no qualifications, the largest differences between these age groups in an individual UK region/country were

\section{Figure 1.35}

\section{Percentage of people aged 50-64 undertaking adult learning in the last year, April 2008 to March 2009}

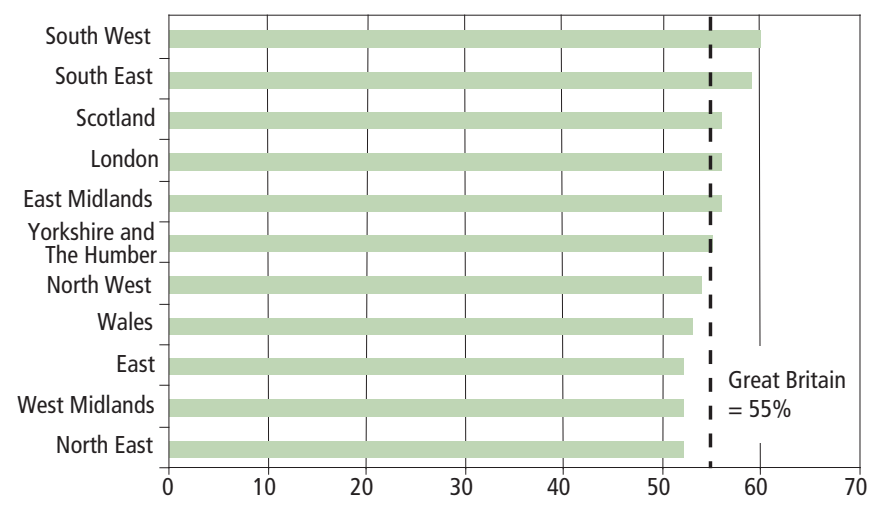

Source: Annual Population Survey, Office for National Statistics
13 percentage points in Northern Ireland (22 per cent of working age population; 35 per cent for those aged 50-SPA) and 9 percentage points in London ( 12 per cent and 21 per cent respectively). The smallest differences between these two age groups were 3 percentage points in the South East and 4 percentage points in the South West.

Figure 1.35 presents estimates for regions and countries of Great Britain of the percentage of people aged 50-64 undertaking learning in 2008/09. Learning includes attending taught courses and tuition, whether leading to a qualification, developing skills for a job or developing practical skills, or simply attending classes for any reason. It also includes studying without taking part in a taught course, keeping up with developments in the type of work a person does and supervised training at work. This is one of the indicators adopted in the Department for Work and Pension's (DWP) Opportunity Age Indicators series (2009, DWP).

The southern regions of England exhibited the highest percentages of people aged 50-64 undertaking adult learning in 2008/09 (the South West, 60 per cent, and the South East, 59 per cent). The East, the North East and the West Midlands had the lowest percentage participation in adult learning, all at 52 per cent, compared with the Great Britain average of 55 per cent.

\section{Uptake of concessionary bus passes}

Concessionary bus passes are a relatively new national initiative by the government, to encourage the older population to be more active and participate in more and new activities, although localised schemes have been run in the past in areas such as London.

\section{Figure 1.36}

Uptake of concessionary bus fare schemes ${ }^{1}$ for people aged 60 and over, 2006 to 2008

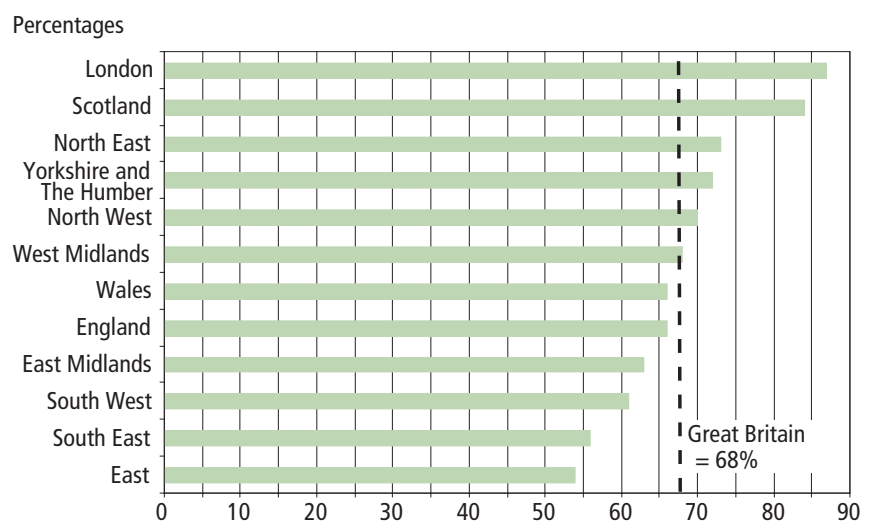

1 Concessionary bus pass schemes became effective as follows: Wales (national) - April 2002; England (local), Scotland (national) - April 2006; England (national) - April 2008.

Source: Department for Transport; The Scottish Government

Figure 1.36 illustrates the three-year average uptake of concessionary bus passes by people aged 60 and over by regions and countries of Great Britain in 2006-08. Highest percentages were found in London (87 per cent) and Scotland 
(84 per cent). Northern regions of England (the North East, 73 per cent; Yorkshire and The Humber, 72 per cent; the North West, 70 per cent) were also above the Great Britain average of 68 per cent.

Lower percentages of bus pass uptake among people aged over 60 were found in the south of England outside London. This is likely to reflect higher levels of car ownership in these regions, as suggested by the overall levels of car ownership (Online table 11.2).

\section{Conclusions}

There is evidence of population ageing in all countries of the UK and regions of England, although it is occurring at different rates due to past fertility and mortality rates and migration into and out of each area. The highest proportions of older people in 2008 were in Wales and the South West of England and the lowest in London and Northern Ireland. However, the older population of Northern Ireland has increased more in the past five years than that of London, partly because some older people move out of London and they are replaced with younger people.

The movement of older people away from London is further demonstrated by estimates for local authority districts which show higher percentages of the population aged 50 and over living around the UK coast and in more rural areas.

The population aged 65 and over is projected to grow steadily

\section{References}

General

The English Longitudinal Study of Ageing (ELSA), available at: www.ifs.org.uk/elsa/index.php

'Focus on Older People', Office for National Statistics (2005), available at: www.statistics.gov.uk/StatBase/Product. asp?vlnk=12348

'The New Performance Framework for Local Authorities and Local Authority Partnerships: Single Set of National Indicators', Communities and Local Government (2007), available at: www.communities.gov.uk/publications/ localgovernment/nationalindicator

'Public Service Agreements: The new performance management framework', HM Treasury (2007), available at: www.hm-treasury.gov.uk/pbr_csr07_psaindex.htm

'National Performance Framework', The Scottish Government (2009), available at: www.scotland.gov.uk/ About/purposestratobjs

'Ageing and Mortality in the UK - National Statistician's annual article on the population', Office for National Statistics (2008), available at: www.statistics.gov.uk/CCI/ article.asp? ID =2079 in all regions between 2006 and 2031. The population aged $50-64$ is projected to grow less rapidly or even decrease in a few regions. London's 50-64 population is projected to increase by the largest percentage of all regions, and its 65 and over population the least. For those aged 65 and over, the greatest percentage increases are projected in Northern Ireland, the East Midlands and the East of England. These areas will face the greatest challenges, in proportion to existing provision, in meeting the needs of the increasing numbers of older people, including the 'oldest old' aged over 85.

In other regions there are greater needs in terms of low incomes. Highest levels of income deprivation - illustrated in a variety of forms such as IDAOPI, pension credit take-up and household income - were generally found in the North East and London. Much of the variation between and within regions appears to reflect the level of rurality of the areas in which older people live. Fuel poverty (only available at regional level) showed a clearer north-south pattern. Life expectancy was also generally higher in the south and midlands, although there was considerable variation within regions.

The ability to work up to - or beyond - state pension age may have implications for wellbeing in older age. Northern Ireland, Wales and the North East had the highest percentages of their population aged 50 to SPA economically inactive in 2008. However, Northern Ireland and the North East (and also Scotland) had the highest percentages among those men aged 50-64 that were in employment who were working full-time.

'Older People's Wellbeing Monitor for Wales' Welsh Assembly Government (2009), available at: http://wales. gov.uk/topics/olderpeople/research/ wellbeingmonitor2009/?lang=en

'Opportunity Age - First Report', Department for Work and Pensions (2008), available at: www.dwp.gov.uk/policy/ ageing-society/strategy-and-publications/opportunity-agefirst-report/

'Opportunity Age Indicators: 2008 Update', available at: www.dwp.gov.uk/policy/ageing-society/evaluatingprogress/opportunity-age-indicators/\#OA_Indcators

'2006-based national population projections for the UK and constituent countries', Office for National Statistics (2008), available at: www.statistics.gov.uk/CCI/article.asp?ID=2085

'Estimating the changing population of the "oldest old"', Office for National Statistics (2008), available at: www. statistics.gov.uk/CCI/article.asp?ID =2089

'Subnational patterns of population ageing', Office for National Statistics (2009), available at: www.statistics.gov. uk/CCl/article.asp? ID =2244

'Employment of the older generation', Office for National Statistics (2009), available at: www.statistics.gov.uk/CCI/ article.asp? ID =2167 
'National Statistician's Annual Article on the Population: a Demographic Review. The third in a series of annual demographic reports of the UK, providing an overview of the latest statistics on the population', Office for National Statistics (2009), available at: www.statistics.gov.uk/cci/ article.asp? ID =2337

\section{Poverty and deprivation}

'Households Below Average Income: An analysis of the income distribution 1994/95 - 2007/08', Department for Work and Pensions (2008), available at: http://research.dwp. gov.uk/asd/hbai/hbai2008/contents.asp

'Income Related Benefits Estimates of Take-up in 2007-08', Department for Work and Pensions (2009), available at: http://research.dwp.gov.uk/asd/irb_2.asp

'Pensioners Incomes Series', Department for Work and Pensions (2009), available at: http://research.dwp.gov.uk/ asd/pensioners_income.asp

\section{Health and care}

'Death registrations in England and Wales, 2007', Office for National Statistics (2008), Health Statistics Quarterly No. 39, pp. 89-97

'Health expectancies in the United Kingdom 2004-06', Office for National Statistics (2008), Health Statistics Quarterly No. 40, pp. 77-80

'Life expectancy at birth and at age 65 by local areas in the United Kingdom, 2005-07', Office for National Statistics (2008), Health Statistics Quarterly No. 40, pp. 81-83

\section{Quality of life}

'Transport Statistics Bulletin: National Travel Survey: 2006', Department for Transport (2006) available at: www.dft.gov.uk/pgr/statistics/datatablespublications/ personal/mainresults/nts2006/

'Measuring societal wellbeing', Office for National Statistics (2007), available at: www.statistics.gov.uk/CCI/article. asp? ID =1882

'Review of the Scotland Wide Free Bus Travel Scheme for Older and Disabled People' (2009), available at: www.scotland.gov.uk/Publications/2009/05/19093131/3

'Transport Research Series: Evaluation of National Concessionary Travel in Scotland' (2009), available at: www. scotland.gov.uk/Publications/2009/05/13144419/0
Small area classifications, indices and statistics

'Urban and rural area definitions: a user guide', Communities and Local Government (2002), available at: www.communities.gov.uk/publications/planningand building/urbanrural

'Rural and Urban Area Classification, 2004', Office for National Statistics (2004), available at:

www.statistics.gov.uk/geography/nrudp.asp

'Northern Ireland Multiple Deprivation Measure 2005', Northern Ireland Statistics and Research Agency (2005), available at:

www.nisra.gov.uk/deprivation/nimdm_2005.htm

'Report of the Inter-Departmental Urban-Rural Definition Group Statistical Classification and Delineation of Settlements February, 2005', Northern Ireland Statistics and Research Agency (2005), available at: www.nisra.gov.uk/geography/default.asp10.htm

'The English Indices of Deprivation 2007', Communities and Local Government (2008): available at: www.communities. gov.uk/documents/communities/pdf/733520.pdf

'Using the English Indices of Deprivation 2007: Guidance', Communities and Local Government (2007), available at: www.communities.gov.uk/documents/communities/ doc/615986.doc

'Statistical Focus on Rural Wales, 2008', Welsh Assembly Government (2008), available at: http://wales.gov.uk/topics/ statistics/publications/focusrural08/?lang=en

'Urban Rural Classification, 2007/2008', The Scottish Government (2008), available at: www.scotland.gov.uk/Publications/2008/07/29152642/0

'Rural Definition and Local Authority Classification', Department for Environment, Food and Rural Affairs, available at: www.defra.gov.uk/evidence/statistics/rural/ rural-definition.htm

Neighbourhood Statistics (England and Wales), Office for National Statistics, available at: www.neighbourhood. statistics.gov.uk

Scottish Neighbourhood Statistics, The Scottish Government, available at: www.sns.gov.uk

Northern Ireland Neighbourhood Statistics, Northern Ireland Statistics and Research Agency, available at: www.ninis.nisra.gov.uk 